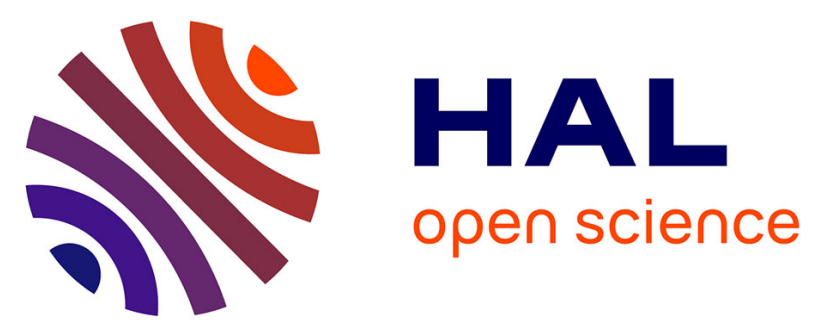

\title{
Development of bending tests for near shear mode interfacial toughness measurement of EB-PVD thermal barrier coatings
}

Jean-Roch Vaunois, Martine Poulain, Pascale Kanoute, Jean Louis Chaboche

\section{- To cite this version:}

Jean-Roch Vaunois, Martine Poulain, Pascale Kanoute, Jean Louis Chaboche. Development of bending tests for near shear mode interfacial toughness measurement of EB-PVD thermal barrier coatings. Engineering Fracture Mechanics, 2017, 171, p. 110-134. 10.1016/j.engfracmech.2016.11.009 . hal01474402

\author{
HAL Id: hal-01474402 \\ https://hal.science/hal-01474402
}

Submitted on 10 Jan 2022

HAL is a multi-disciplinary open access archive for the deposit and dissemination of scientific research documents, whether they are published or not. The documents may come from teaching and research institutions in France or abroad, or from public or private research centers.
L'archive ouverte pluridisciplinaire HAL, est destinée au dépôt et à la diffusion de documents scientifiques de niveau recherche, publiés ou non, émanant des établissements d'enseignement et de recherche français ou étrangers, des laboratoires publics ou privés.

\section{(ㅇ)(1) $\$$}

Distributed under a Creative Commons Attribution - NonCommerciall 4.0 International 


\title{
Development of bending tests for near shear mode interfacial toughness measurement of EB-PVD thermal barrier coatings
}

\author{
Jean-Roch Vaunois ${ }^{\mathrm{a}}$, Martine Poulain ${ }^{\mathrm{b}, *}$, Pascale Kanouté ${ }^{\mathrm{b}}$, Jean-Louis Chaboche ${ }^{\mathrm{b}}$ \\ ${ }^{\text {a }}$ Snecma Villaroche - SAFRAN Group, F-77550 Moissy-Cramayel, France \\ ${ }^{\mathrm{b}}$ Onera - The French Aerospace Lab, F- 92322 Châtillon, France
}

\begin{abstract}
Mechanisms leading to degradation of the mechanical adhesion of thermal barrier coatings (TBCs) used in aircraft turbines are numerous and complex. Direct measurement of interface toughness as a function of thermal cycling exposure must be a component of any practical approach to lifetime assessment based on a spallation criterion. This paper outlines several adhesion tests, where the multilayered system undergoes different mechanical loading. The notion of mode mixity angle is reminded and a method for its determination is described. Of course, this method to compute the mode mixity angle can be useful for any thin film delamination problem.

Some results on the TBC adhesion energy are presented, relating to both the temperature and the time-of-aging for relevant mode mixity consistent with the spallation configurations observed from feedback on ex-service blades. The effect of the residual stresses induced during thermal cycling is considered here, in order to derive the intrinsic critical energy release rate. The whole set of data enables a description to be made of the intrinsic interfacial toughness decreasing under both thermal aging and mechanical loading. Finally, an energetic approach is used to compare this intrinsic interfacial toughness to the elastic stored energy during thermal cycling, in order to assess the lifetime corresponding to spontaneous spallation.
\end{abstract}

\section{Introduction}

Thermal barrier coatings (TBCs) represent a major breakthrough in aeronautical material science. Coupled with the internal cooling of components, these advanced multilayered systems are designed to reduce the temperature of the underlying metallic alloy substrate while withstanding turbine inlet temperatures of gas reaching $1500{ }^{\circ} \mathrm{C}$ or more $[1,2]$.

TBC systems usually involve four layers [3]: the substrate metallic alloy, a metallic bond coat protecting the substrate from oxidation, a thermally grown oxide (TGO) due to the oxidation of the bond coat (alumina hereby), and a porous ceramic topcoat, which is the actual insulating layer and can decrease the temperature in the depth down to a few ${ }^{\circ} \mathrm{C} . \mu \mathrm{m}^{-1}$. In our study, the yttria partially stabilized zirconia (YPSZ) topcoat is about $150 \mu \mathrm{m}$ thick and electron beam deposited, with a columnar structure, as used on rotating blades. The presence of interfaces is consequently intrinsic to such a system, characterized by heterogeneities and discontinuities in thermal and mechanical properties between the layers [4].

\footnotetext{
* Corresponding author at: Onera - Department of Metallic Materials and Structures, BP72 - 29 avenue de la Division Leclerc, FR-92322 Chatillon Cedex, France.

E-mail address: Martine.Poulain@onera.fr (M. Poulain).
} 


\section{Nomenclature}

a half-crack length for 4PB, I4PB and buckling configurations. It is the crack length for unsymmetrical cases of $4 \mathrm{ENF}$ and edge delamination.

A damage parameter

bse back-scattered electrons

$d A \quad$ elementary increase of fractured surface

$D \quad$ damage parameter

$E_{i} \quad$ Young's modulus for Layer i

$E_{\text {int }} \quad$ stored elastic energy

F applied load

$G \quad$ energy release rate

$G_{c} \quad$ interfacial fracture toughness

$G_{I C} \quad$ interfacial fracture toughness in the pure crack opening mode (Mode I)

$K \quad$ interface stress intensity factor

l characteristic distance

$M \quad$ applied moment

$Q_{D} \quad$ damaging process activation energy

$r \quad$ distance to the crack tip

$R \quad$ gas constant

SEM Scanning Electron Microscopy

$u \quad$ displacement

$x, y, z \quad$ Cartesian coordinate system

$\beta, \varepsilon \quad$ elastic mismatch Dundurs parameter

$\delta_{1} \quad$ shear opening of the crack flanks

$\delta_{2} \quad$ normal opening of the crack flanks

$\lambda$ interfacial parameter

$v_{i} \quad$ Poisson's ratio for Layer i

$\sigma_{\mathrm{ij}} \quad$ components of the stress tensor

$\sigma_{\text {res }} \quad$ residual stress

$\psi \quad$ mode mixity angle

Multiple failure mechanisms leading to spallation of the topcoat have been observed in the literature. We can quote, for instance, the review papers by Evans et al. [5,6], and we can also refer for example to Song [7], Spitsberg et al. [8] and Yanar et al. [9]. The deleterious crack propagates between the topcoat and the bond coat, at one or both of the TGO interfaces, or even by a complicated pathway going right through the TGO, depending on the interfacial undulation growth promoted by the TGO thickening [10]. Actually, these two phenomena are well known to jointly lead to TBC spallation [11,12].

This study is aimed at understanding and reproducing on laboratory specimens the predominant TBC failure modes that we observed on ex-service turbine blades [13,14]. It turns out that large-scale delamination from free edges or buckling debonding such as described in the literature [15] are involved. Knowing that the second mechanism causes ridge cracks [16], we can suspect that the failure mechanisms in our TBC system are strongly governed by oriented Mode II interfacial crack propagation [17].

Interfacial crack propagation has been studied mainly within elastic fracture mechanics and an overview of the theoretical framework is provided by Hutchinson and Suo [18] and Leguillon [19]. The main particularity is that, in the presence of an interface with two different materials, the interfacial Stress Intensity Factor (SIF) is a complex quantity and the displacement and stress solutions present oscillatory singularities. However, the Griffith criterion can be suitable for the study of the crack growth at interfaces, as mentioned by Leguillon [19] and Martin [20]. It is then necessary to define the toughness at the interface. In the context of TBC, some authors have proposed a criterion based on an energy balance to define the lifetime corresponding to spallation [5,21]. The main difficulty in such an approach also concerns the characterization of the interfacial toughness, which depends on the mode mixity, as demonstrated experimentally by Wang [22] and Lie [23]. Whatever the studied multilayered system [24-26], it appears to be of prime importance to properly determine the precise mode mixity angle during the interfacial toughness characterization [17] for each loading configuration considered.

The goal of this work was thus to set up and use adhesion tests, which induce an interfacial crack propagation with a mode mixity angle representative of conditions occurring in TBC spallation on blades. An important aspect was therefore to evaluate the interfacial toughness as a function of the thermal loading history. Since the topcoat spalls after cooling to room temperature, i.e., when the compressive thermal stresses are the highest, we have chosen to perform cyclic oxidation tests under laboratory air at atmospheric pressure. Thus, the purpose of the mechanical tests is to quantify the interfacial toughness of the TBC system in the as-received state, or after those aging treatments.

Various kinds of mechanical tests (tensile and shear test methods, bending tests, scratch and indentation tests, etc.) can be used to investigate the practical adhesion of coatings to a substrate, like in TBC systems [17]. The challenge is to precisely 
evaluate the relevant interfacial toughness in conjunction with an elastic fracture mechanics approach (the crack mainly propagates when the system is at a low temperature, within the elastic range) towards TBC durability assessment.

This investigation proposes a challenging adaptation of existing 4-point bending tests [27,28], in order to measure the adhesion energy of the topcoat, i.e., the strain energy release rate required for stable crack propagation at the ceramic/ substrate interface. In addition to these experimental aspects, both analytical and numerical finite element calculations are presented to explain how the strain energy release rate is derived from the bending test data for various loading conditions.

The paper is organized in the following way. Predominant delamination scenarios on the studied turbine blade TBC system, as well as the mechanical tests developed for interfacial toughness determination, are described in Section 2. Whereas this introductory experimental part is focused on the damaging phenomena identified, setting up three suitable bending tests and experimental procedures, Section 3 presents the numerical methods for determining the interfacial toughness and mode mixities for interfacial crack growth. We review the necessary theoretical background of the mode mixity angle and we then provide the finite element analysis of the bending tests and of the edge delamination and buckling configurations actually observed on turbine blades. Section 4 is devoted to the presentation of the whole set of adhesion energy test results and their discussion, including in particular the sensitive matter of residual stress potential contribution. A simple model is then applied to describe the changes in the interfacial fracture toughness under both thermal aging and mechanical loading of the interface. This study is part of a broad approach that is aimed at building a lifetime assessment model physically based on the energetic consideration of spallation [13,21,29]. We finally present the use of the results, to predict the lifetime by means of a spontaneous spallation criterion defined from this energetic approach.

\section{Studied configurations and experimental procedures}

\subsection{Delamination scenario on a turbine blade TBC system}

This study is motivated by the need to develop tools for assessing the lifetime of the TBC system used in high-pressure turbine blades for turboengines. The system as schematically described in Fig. 1 is mainly composed of a bond coat (Ni,Pt)Al in our case) deposited on the substrate (nickel-based single crystal superalloy: AM1 in this case ${ }^{1}$ ), and a ceramic topcoat (YPSZ), the thermal barrier itself, made by electron beam physical vapor deposition (EB-PVD).

Oxidation takes place during service at the interface between the bond coat and topcoat, especially in the most heated zones, leading to the thickening of an $\mathrm{Al}_{2} \mathrm{O}_{3}$ oxide layer. Its thickness evolves from about $0.5 \mu \mathrm{m}$ after ceramic deposition to 5-6 $\mu \mathrm{m}$ after a hundred hours at service temperature. Simultaneously, this oxide layer may become rumpled, with a progressive increase of interfacial roughness, under low-scale complex mechanisms that involve the various layers.

The high level of internal stresses, both in-plane (thermal mismatch stresses, oxide growth stresses, etc.) and out-of-plane (at the lower scale), enhanced by the rumpling mechanisms, progressively deteriorate the oxide region (cavities at the interfaces or inside $\mathrm{Al}_{2} \mathrm{O}_{3}$, microcracks, etc.). At the macroscopic level, these mechanisms reduce the overall interfacial toughness, which, associated with the increase of the elastic stored energies in the adjacent layers, leads to delamination. It is followed by macrocrack propagation at the interface between the bond coat and topcoat, which ends by the complete spalling of the ceramic topcoat over significant portions of the blade surface.

The TBC system is globally subjected to external loads that combine mechanical and thermomechanical stresses, withstood mainly by the substrate. These macroscopic stress systems are generally assumed to be globally in-plane, where the thin layers are subjected to the thermomechanical strains imposed by the (thick) substrate.

Depending on the considered blade area, the propagation of the interfacial delamination involves both spatially varying interfacial toughness and various possible mixities of the propagation modes. In order to select the experimental configurations needed to cover laboratory toughness measurements under realistic loading conditions, two ideal crack propagation cases from the literature [30-32] have been examined. These two configurations are consistent with the spalled zones observed from feedback on ex-service blades, as shown in Fig. 2 [13].

The first case is called "edge delamination" and occurs when a portion of TBC has already spalled, leaving a sharp edge and a crack between the TBC and the substrate (or bond coat). The crack of length $a$ will propagate along the interface when thermal cooling of the system is applied, leading to complete spallation. Fig. 2b illustrates the configuration retained for the following simulation.

The second ideal case of propagation is called "buckling" and is characterized by a crack of length $2 a$ between the topcoat and the bond coat, but the debonding topcoat is not completely spalled off and is held by its adhering sides. Like the previous scenario, when cooling occurs in such a system, the crack tends to propagate outward from the initial buckle.

These two configurations, resulting from in-service conditions, induce interfacial crack propagation close to a pure shear mode, as will be demonstrated later (see Section 3). However, many authors $[18,24,33,34]$ have already pointed out the strong dependence of the interfacial toughness on the crack propagation mode. Therefore, specific mechanical experiments are needed to obtain relevant interfacial toughness results regarding the mode propagation occurring in service.

\footnotetext{
${ }^{1}$ Composition of AM1 (wt.\%): Al 5.2 - Cr 7.8 - Co 6.5 - Ta 7.9 - Ti 1.1 - W 5.7 - Mo 2.0 - Ni bal.
} 


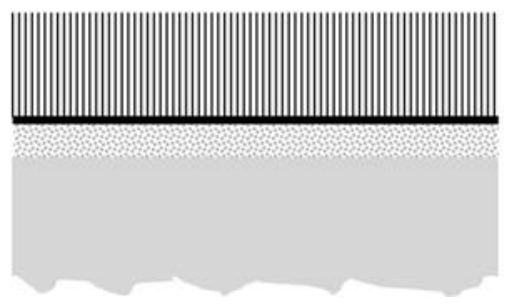

topcoat

TGO

bond coat

superalloy

Fig. 1. Multilayered structure of a TBC system.

(a)
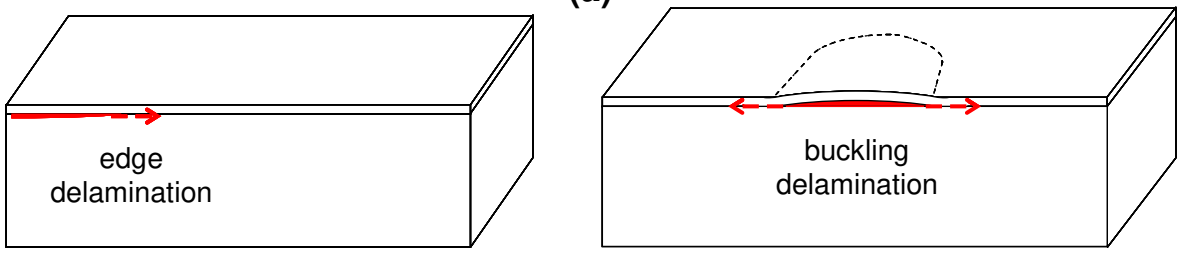

(b)
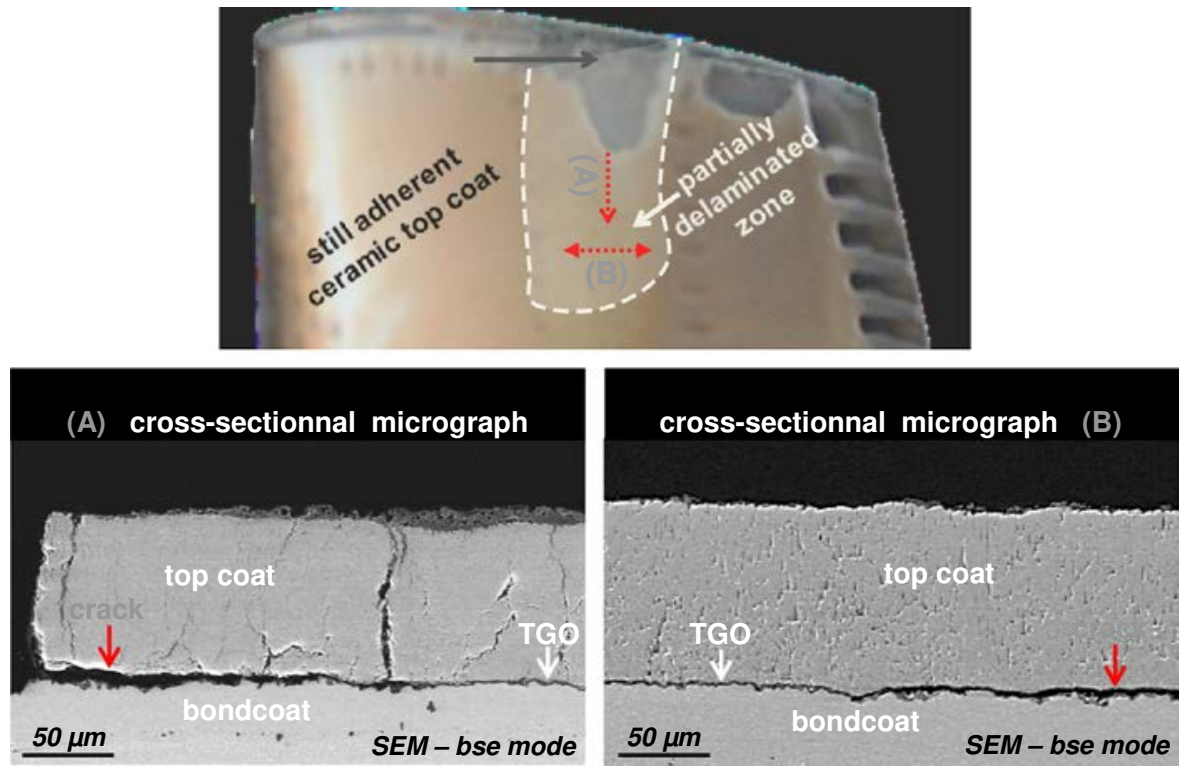

Fig. 2. Interfacial crack propagation: (a) Ideal cases inspired by Choi et al. [15]) - (b) Actual delamination scenario (identified from the service feedback).

\subsection{Mechanical tests for interfacial toughness determination}

The development of adhesion tests for TGO growing on protective coating used to improve oxidation resistance of metallic components, or at the TBCs ceramic/metal interface during aging at high temperature, has been a major issue for a long time $[35,36]$. This thin oxide scale appears under thermal cycling service conditions, from the oxidation of aluminum present in the coating or in the bond coat due to oxygen diffusion through the oxygen ion-conductive YPSZ porous topcoat. In order to further reduce diffusion to the superalloy, the TGO should be continuous, dense, and the adhesion strength between the metal and this thermally grown oxide layer is of prime importance to avoid oxidation of metallic components.

Interfacial indentation tests [37-39], push-out tests [40], scratch tests [41], etc., have already been evaluated with regard to their efficiency in delivering relevant interfacial toughness data. The current challenge is to ensure that the laboratory tests proposed produce similar effects to those found in service. Some adhesion tests, such as the Brazilian test [42], can provide a wide range of loading phase angles for interfacial toughness measurements. However, this test requires a sandwich disk specimen with geometric parameters that are not easily compatible with the TBC multilayered structure, and does not ensure stable crack propagation. 
Our work is focused on the development and use of three configurations of 4-point bending tests enabling a sufficiently large crack propagation mode domain to be covered by combining them. When considering bending tests as mentioned by Théry [21], an experimental difficulty arises relating to the very small thickness and extreme brittleness of the EB-PVD ceramic layer. Following a suggestion by Hofinger et al. [43], it is hence useful to adhere a stiffener plate to the top of the TBC sample $[44,45]$ in order to achieve sufficient griping capabilities, and to increase the crack driving force (the elastic energy released by the crack propagation). This prevents the topcoat from fracturing and thus enables stable interfacial crack propagation to be achieved under a limited external loading, reducing the risk of overall plastic flow in the substrate layer.

Moreover, it is well known that several microscopic effects contribute to the adhesion degradation, so the weakest interface of an EB-PVD TBC system can be the topcoat/TGO or the TGO/bond coat interface. However, when considering the macroscopic interfacial toughness measurement, only ceramic/metal debonding is of relevant interest without any assumption regarding the crack pathway, possibly complicated and mixed during the adhesion test.

\subsubsection{Presentation of the system and configuration testing}

The first selected test developed at Onera [45,46] for EB-PVD TBC interfacial toughness evaluation was the 4-point bending test [47] (4PB) already used for testing APS (Air Plasma Sprayed) TBCs on laboratory specimens [43,48,49]. It has been adapted to quantify the adhesion energy of EB-PVD TBCs, by inducing the topcoat delamination before spontaneous spallation on laboratory specimens [28]. It should be noted that bending tests can possibly be used in situ [50].

During such an adhesion test, a plate specimen is subjected to a downward force, that leads to interfacial crack propagation from the center of the specimen towards the edge of the specimen.

Fig. 3 presents the geometry specifications of the bending test specimen used on TBC by Théry [45]. Plate-shaped thermal barrier coated nickel-based superalloy samples ( $60 \mathrm{~mm}$ in length $\times 1.2 \mathrm{~mm}$ thick $\times 8 \mathrm{~mm}$ in depth) were considered. The multilayered system includes a $7 \mathrm{wt} . \% \mathrm{Y}_{2} \mathrm{O}_{3}-\mathrm{ZrO}_{2}$ ceramic topcoat deposited by EB-PVD onto a single-crystal substrate AM1 superalloy protected with a $\beta-(\mathrm{Ni}, \mathrm{Pt}) \mathrm{Al}$ bond coat. The single crystal substrate edges were oriented along the $\left\langle\begin{array}{lllll}0 & 0 & 1\end{array}\right\rangle$ directions using the back-reflection Laue method.

A $1 \mathrm{~mm}$ thick stiffening layer was added to the TBC sample, in order to increase the elastic stored energy, allowing interfacial crack propagation under moderate loading and reducing the risk for overall plastic flow in the substrate layer. For this purpose, a stainless steel (AISI 304L) having a high Young's modulus (195 GPa) has been chosen as a stiffener material. The thicknesses and the properties of the different layers of the plate specimens subjected to a downward force are given in Table 1. The total thickness of the bending test specimens, including all of the layers, is either $2.3 \mathrm{~mm}$ or $3.3 \mathrm{~mm}$. The distances between the load application points are shown in Fig. 3. Although some of the layers are anisotropic, the theoretical and numerical analyses in this work are made considering the approximation of elastic isotropy. For the substrate the Young's modulus parallel to the $\langle 100\rangle$ direction is used as isotropic value.

The 4PB test appears to be a fruitful configuration, but it corresponds to an interfacial propagation that is not sufficiently far from Mode I, currently corresponding to mode mixity angles between 30 and $45^{\circ}$. In fact, as shown in many experimental studies $[18,24,33,34]$, the toughness variation is much less significant for small mixity angles (between 0 and $45^{\circ}$ ) than for

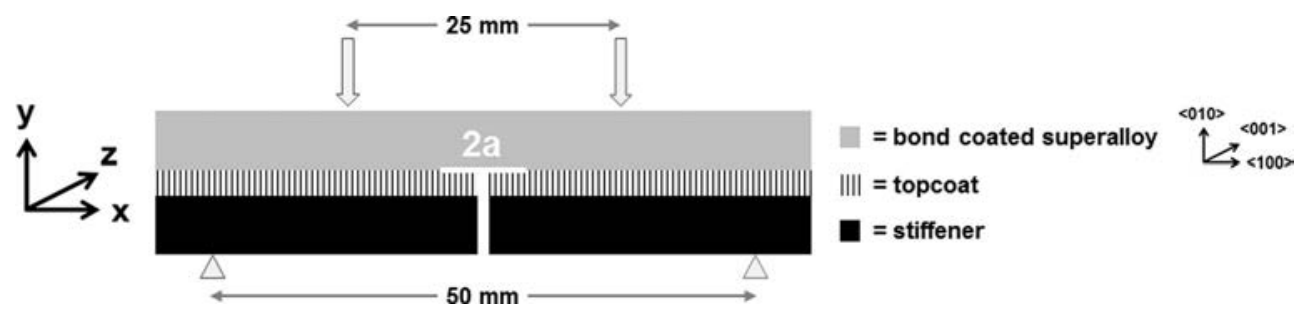

Fig. 3. Geometry of the $4 \mathrm{~PB}$ test specimen and position of the crack of length $2 a$ (the $1 \mathrm{~mm}$ thick notched stiffener plate and YPSZ ceramic layer are at the bottom).

Table 1

Mechanical and thermal data of the different layers of the bending test specimens, deduced from a literature review (see for example [51-54]) or provided by the suppliers*.

\begin{tabular}{lllll}
\hline Layer & Nominal thickness & Young's modulus & Poisson's ratio & Thermal expansion coefficient \\
\hline Superalloy & $1 \mathrm{~mm}$ & $129.5 \mathrm{GPa}$ & 0.408 & $1.4 \cdot 10^{-5} \mathrm{~K}^{-1}$ \\
Bond coat & $50 \mu \mathrm{m}$ & $120 \mathrm{GPa}$ & 0.3 & $1.5 \cdot 10^{-5} \mathrm{~K}^{-1}$ \\
TGO & $0.5-5 \mu \mathrm{m}$ & $380 \mathrm{GPa}$ & 0.2 & $0.6 \cdot 10^{-5} \mathrm{~K}^{-1}$ \\
Topcoat & $150 \mu \mathrm{m}$ & $30 \mathrm{GPa}$ & 0.1 & $1.0 \cdot 10^{-5} \mathrm{~K}^{-1}$ \\
Glue* $^{*}$ & $100 \mu \mathrm{m}$ & $3.0 \mathrm{GPa}$ & 0.4 & 1 \\
Stiffener* $^{*}$ & $1 \mathrm{~mm}$ & $195 \mathrm{GPa}$ & 0.3 & 1 \\
\hline
\end{tabular}

* Stiffener’s provider: Comptoir Général des Métaux - Glue’s provider: CYTEC Engineering Materials. 
larger ones, when approaching mixities near Mode II. Therefore, extrapolating the measured toughness from the 4PB specimen (as done, for instance, by Thery [45]) appears really questionable.

In order to go beyond this approach, we chose to further develop fracture toughness tests presenting a near Mode II propagation, or at least one sufficiently close to the expected mode mixities under blade conditions. The first one is the Inverted 4-point bending test (I4PB) suggested in [17] due to potentially leading to near Mode II delamination. This particular test has the great advantage of having exactly the same geometry as that of the previous test (4PB), so we can use the same specimen preparation, which will be described in Section 2.2.2. This test differs from the classical 4PB test in the direction of the applied loading (or the positioning of the specimen in the testing machine, see Fig. 4). The crack propagation is thus significantly impacted, inducing a nearly shear crack propagation, as will be demonstrated in Section 3.

Moreover, we consider another crack propagation test, applicable for plate specimens, the 4-point End-Notched Flexure (4ENF). This test is widely used for composite materials, and known to present a near Mode II propagation [27,55,56]. However, a Mode II situation is more resistant to crack propagation than Mode I, and the challenge is to apply such a technique for our material system, which presents a mechanical behavior that is quite different from that of composite laminates. The test sample is shown in Fig. 5. The thickness of the stiffener plate used for the 4PB test has been optimized by changing the thickness to $2 \mathrm{~mm}$ (instead of $1 \mathrm{~mm}$ ), in order to increase the elastic energy that can be released by the crack propagation under this configuration (see Table 2 in Section 3.2.2.).

For these three tests, the initial crack in the sample must allow a steady state propagation, i.e., long enough to avoid the initiation area and the geometrical singularities of the specimen (notch, end of the specimen), but not too long to stay within the inner supports.

All of these bending tests are carried out with the aim of obtaining useful data enabling the interfacial failure in the two delamination mechanisms described in Fig. 2 to be estimated. As reminded by Hutchinson and Hutchinson [17], the interfacial toughness cannot be predicted, so experimental techniques for delamination toughness measurement are needed when either large scale buckling or edge delamination are involved.

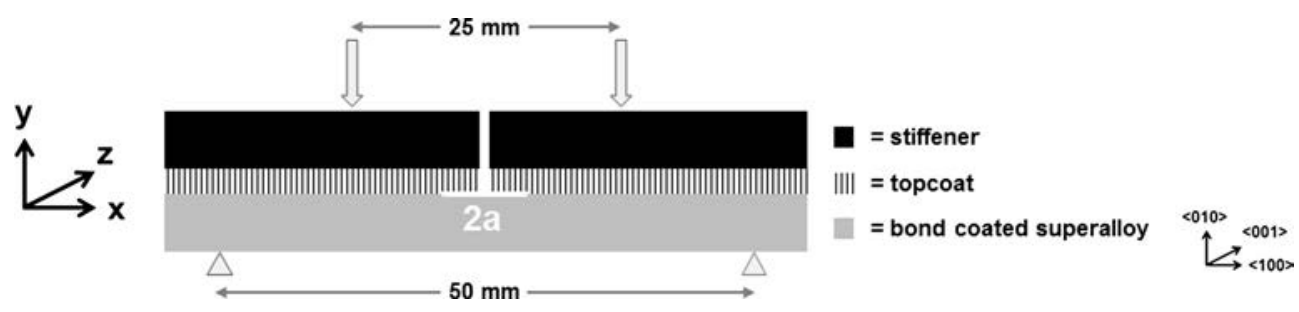

Fig. 4. Geometry of the I4PB test specimen and position of the crack of length $2 a$ (the $1 \mathrm{~mm}$ thick notched stiffener plate and YPSZ ceramic layer are above).

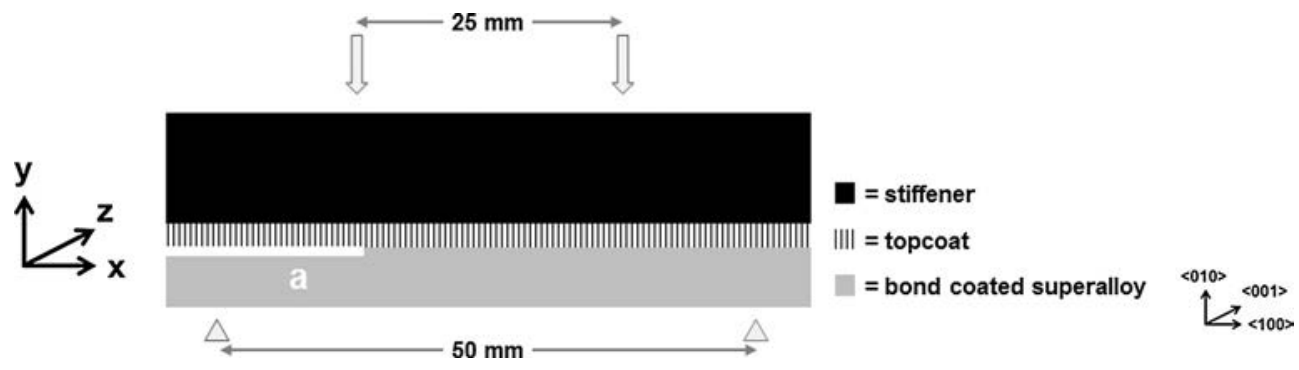

Fig. 5. Geometry of the 4 ENF test specimen and position of the crack of length $a$ (the $2 \mathrm{~mm}$ thick stiffener plate is above).

Table 2

Elastic energy release rate obtained by various methods (results in J. $\mathrm{m}^{-2}$ ). In 5 th column is given the average between the 3 values at $10^{-8}, 10^{-7}, 10^{-6} \mathrm{~mm}$ perturbations.

\begin{tabular}{lllllll}
\hline Specimen & $a(\mathrm{~mm})$ & Analytical & Parks $\left(10^{-8} \mathrm{~mm}\right)$ & Parks (average) & Variation of potential energy & VCCT \\
\hline 4PB & 5 & 4.8956 & 4.8932 & 4.884 & 4.900 & 4.915 \\
I4PB & 5 & & 2.4112 & 2.407 & 2.419 & 2.399 \\
4ENF & 20 & & 0.3389 & 0.3388 & 0.3395 & 0.3398 \\
Edging & 4 & 49.688 & & & 49.723 & 49.970 \\
\hline
\end{tabular}




\subsubsection{Specimen preparation}

Plate-shaped thermal barrier coated Ni-based superalloy samples (YPSZ EB-PVD topcoat/ $\beta$-(Ni, Pt)Al bond coat/AM1 superalloy, $60 \mathrm{~mm}$ in length $\times 1.2 \mathrm{~mm}$ thick $\times 8 \mathrm{~mm}$ in depth) have been made for all the adhesion tests.

It should be noted that the bond coat is grit-blasted prior to YPSZ deposition. This surface finishing industrial process has a double beneficial effect on the topcoat adhesion: first, it promotes nucleation of a continuous-protective columnar alumina scale from the preheating stage; second, it ensures anchoring between the ceramic layer and the metallic component. Indeed, this early roughness can slow down potential crack propagation, and therefore significantly enhances the interface toughness. Otherwise, if the interface is smooth, the slightest crack could propagate over a very large area and then the topcoat would be poorly adhesive. In our case, however, in order to eliminate problems related to interface crack initiation and to induce a crack more or less propagating under steady state conditions, a pseudo interfacial pre-crack is obtained by sparingly grit-blasting a region $1 \mathrm{~mm}$ wide around the sample center (for 4PB and I4PB specimens). This suppressed grit blasting area extends much further than for the $4 \mathrm{ENF}$ sample, over about $19 \mathrm{~mm}$ from the end of the specimen.

In order to adhere the steel stiffener as strongly as possible to the naturally rough topcoat (EB-PVD deposition process), it is grit-blasted beforehand, in order to increase the surface roughness thereby enabling the glue to adhere well to it.

However, the most critical point was the choice of the adhesive layer, and many characterizations have been done to select the most appropriate one for our application. Three different glues with high strength and toughness have been considered: two kinds of component epoxy paste adhesive (Araldite ${ }^{\circledR} 2011$ and $3 \mathrm{M}^{\mathrm{TM}} 9323 \mathrm{~B} / \mathrm{A}$ ) and an adhesive film (FM1000 Cytec $^{\circledR}$ ). The first technique that we performed to assess their bonding performances was a pull-off test, which did not allow the most appropriate glue for our adhesion tests to be determined because of poorly repeatable results. Therefore, the preselected glues have been sorted out by means of a specific test involving shear forces. For this simple lap shear (SLS) test, sandwich specimens are made by gluing two steel plates $(60 \times 8 \times 1 \mathrm{~mm})$ with a lap joint about $10 \mathrm{~mm}$ wide.

During the bending tests, it is important for all of the layers to be uniformly thick. Therefore, special care must be taken when the stiffener is glued onto the topcoat. To this end, we used an adjustable clamp system to hold together the two parts of the specimen during the necessary curing operation $\left(175^{\circ} \mathrm{C} / 1 \mathrm{~h}\right.$ for $\mathrm{FM} 1000,65^{\circ} \mathrm{C} / 2 \mathrm{~h}$ for $3 \mathrm{M} 9323,60^{\circ} \mathrm{C} / 1.5 \mathrm{~h}$ for Araldite).

Fig. 6 shows the load/displacement curves related to the three different glues while performing the SLS test. We can see that the two structural paste adhesive joints were sheared during the test, under a similar load value. Conversely, when using the adhesive film, the joint did not break; the specimen-constitutive steel necked and finally broke. The FM1000 adhesive film was thus chosen to adhere the steel stiffener to our topcoat.

In order to complete the specimen preparation for the 4PB and I4PB tests, it is necessary to make a central notch. A wire saw (diameter: $300 \mu \mathrm{m}$ ) was used, in order to obtain a straight bottom end. According to the observation by means of a stereoscopic optical microscope, we ceased to cut into the topcoat layer as near as possible to the bond coat layer, in order to achieve maximum shear at the topcoat/bond coat interface during the first stages of the bending tests [24]. Fig. 7 shows one example of such cutting.

We assumed at the beginning that the 4ENF test does not require any transverse notch. However, a great problem that we faced was that no crack propagation occurred when performing the preliminary tests, because no efficient pre-crack was present at the interface. Even if the interface has a large region of poor adhesion induced by suppressing the grit-blasting over about $19 \mathrm{~mm}$ from the end of the sample, the topcoat still adheres to the bond coat. Moreover, the specimen end is outside the loading rollers (see Fig. 5) and therefore the shear stresses are very low in this end region.

In order to be certain to obtain an initial crack long enough to reach the inner support of the bending system (at $17.5 \mathrm{~mm}$ from the end of the specimen), we cut one of the neighboring layers (steel stiffener or superalloy substrate) up to the TBC interface. After that, we initiate the crack with a little shock, controlling the propagation distance by clamping the part of the specimen where we do not want the crack to propagate. As illustrated in Fig. 8, we end up with a specimen having a really long initial crack, useful to correctly obtain stable propagation for the 4ENF loading case.

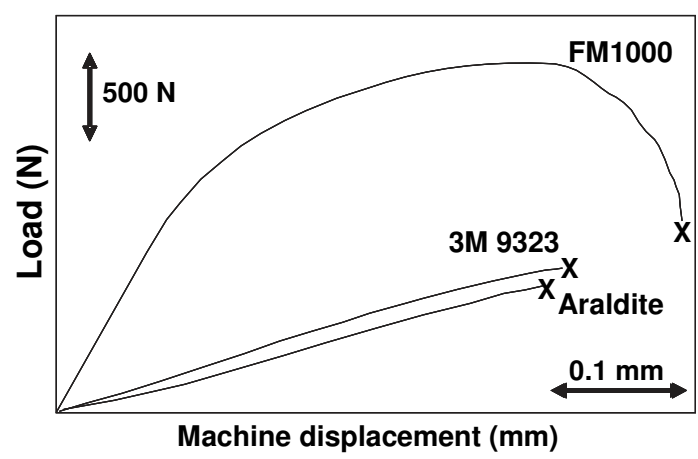

Fig. 6. Load/displacement curve for the SLS test of the 3 glues. 

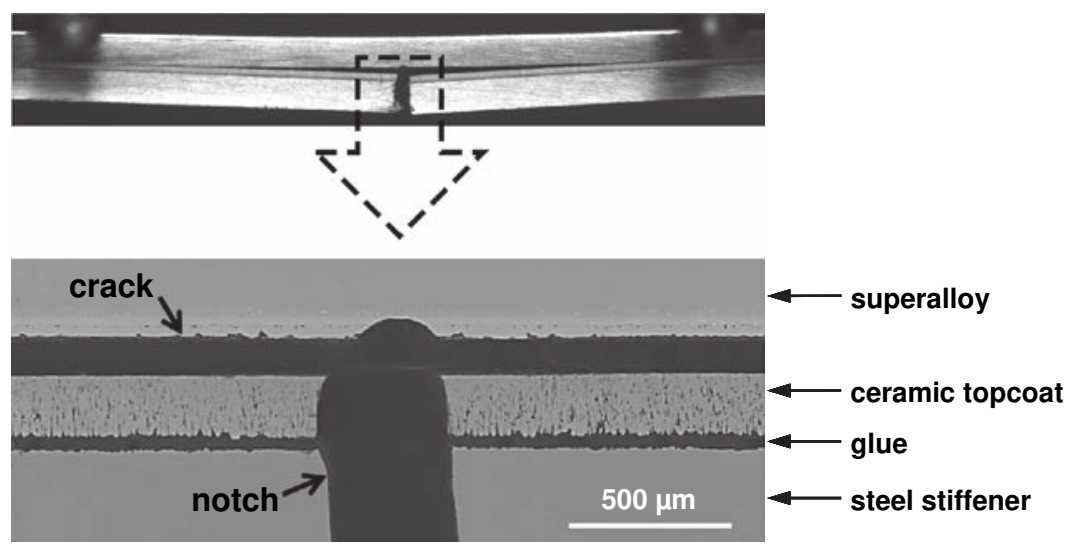

Fig. 7. Example of stiffener and ceramic topcoat cutting on a $4 \mathrm{~PB}$ specimen.

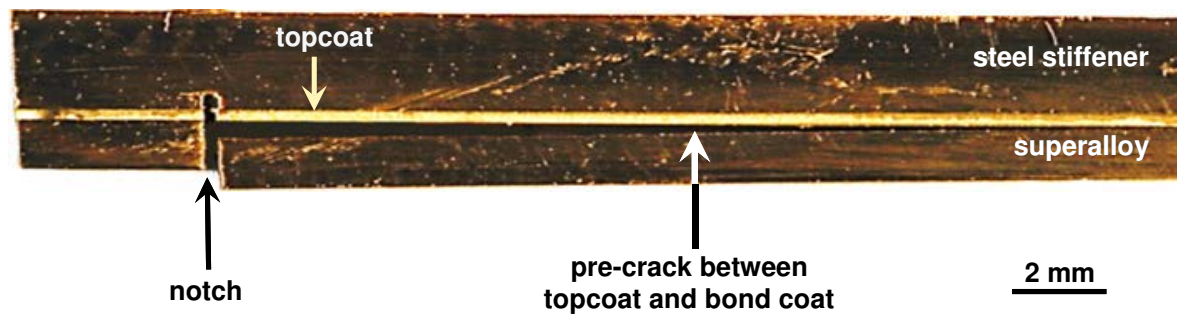

Fig. 8. Pre-crack initiated "by hand" for a 4 ENF specimen.

\subsubsection{Bending tests and toughness measurements}

Prior to the specimen preparation (gluing and notching of the stiffener plate) thermal cycling exposures that simulate inservice damaging conditions were conducted in an automated device under atmospheric pressure. Each cycle is composed of 3 phases, $8 \mathrm{~min}$ of heating, a $60 \mathrm{~min}$ dwell time at $1100^{\circ} \mathrm{C}$ (or 1070 or $1150{ }^{\circ} \mathrm{C}$ ) and a 4 min forced-air cooling down to $100{ }^{\circ} \mathrm{C}$.

In multilayered systems, during bending tests such as 4ENF or 4PB for instance, when the measured displacement increases under a constant load, we observe more or less stable crack propagation. This load plateau is then the critical force needed to drive the crack (see a few examples in Fig. 9).

It is then easy to use finite element simulations (described later in Section 3.2) to obtain the critical interface toughness, from the external load measured at the plateau, within the context of a steady state propagation and assuming linear elasticity. Large displacement simulations have shown that the relation between the applied load and the energy release rate remains linear.

Prior to the presentation of our experimental sets, the following section explains in detail the procedure used to derive several facture mechanics quantities as the energy release rate.

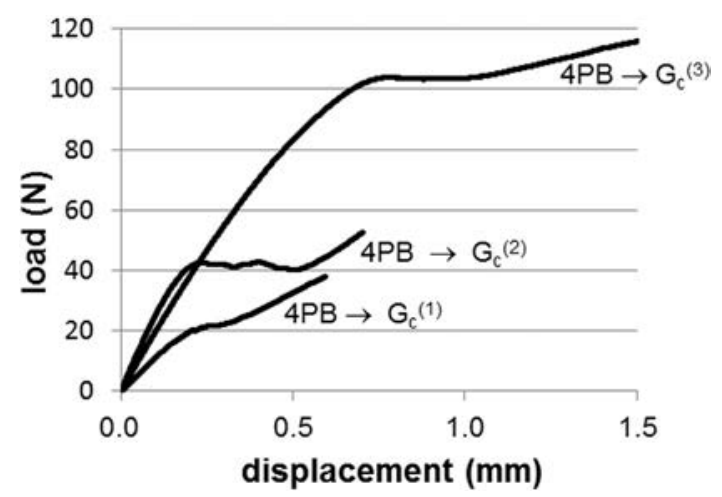

Fig. 9. Example of force/displacement registered curve on various aged samples $G_{c}^{(1)}<G_{c}^{(2)}<G_{c}^{(3)}$. 


\section{Numerical methods for determining the energy release rate and mode mixities}

In order to correctly interpret the experiments, we need both the calculation of the elastic energy released during the crack propagation at the interface and the mode mixity introduced by the internal and external loads. These quantities are defined within the context of a linear elastic fracture mechanics framework. Consistently, this continuum mechanics approach macroscopically considers the crack as propagating between the bond coat and the ceramic topcoat. It neglects the TGO itself as being of a too small thickness (from 0.5 to about $5 \mu \mathrm{m}$ ), as well as all of the local heterogeneities (grains, roughness of the oxide layer, etc.). Due to the different elastic characteristics between the bond coat and the ceramic layer, the crack tip singularity is complex, with oscillating fields (very near to the tip). Many studies of this problem can be found in the literature [18,26,33,34,57-60].

Though some of the layers are anisotropic, we approximate the problem by considering all of the layers to be elastically isotropic. In fact, the single crystal is anisotropic, with the cubic symmetry, but the substrate in the sample is oriented in the direction $\left\langle\begin{array}{lll}0 & 0 & 1\end{array}\right\rangle$, so that it essentially works in tension and compression in that direction. Moreover, the TBC is transversely isotropic and we assume that the out-of-plane property does not significantly impact the results for such a thin layer.

The mode mixity angle associated with the current loading configurations (far fields) is needed, since the crack growth resistance appears to be greatly dependent on this quantity. It enables us to compare the different loading states at the crack tip, for any propagating interfacial crack. In particular, it enables the various adhesion tests and the propagation scenarios under typical blade conditions (see Section 4.2) to be compared on a common scale.

\subsection{Theoretical definitions of the mode mixity angle}

The approach followed in this paper is based on the use of a finite element analysis of the TBC system under its external loading, in order to extract both the elastic energy release rate and the mode mixity angle. In this context, it is possible to determine this mode mixity angle by two methods, theoretically identical, but somewhat different within a numerical computation. The mode mixity angle can then be obtained, on the one hand, from the displacement of the crack flanks (displacement of the upper flank relative to the lower one), and, on the other hand, from the stress field forward of the crack tip, where the layers are still adherent. However, the stress field, as a derivative of the displacements, is more sensitive to mesh discretization, especially near the crack tip.

We first express the singular stress field ahead of the crack tip and the crack opening displacements as the components normal and tangential to the plane interface (the crack plane). These analytical solutions $[18,60]$ correspond to a crack at the interface between two semi-infinite bodies, treated in plane strain. As a function of $r$, the distance to the crack tip, they are expressed as:

$$
\begin{aligned}
& \sigma_{22}+i \sigma_{12}=\left(K_{1}+i K_{2}\right)(2 \pi r)^{-1 / 2} r^{i \varepsilon} \\
& \delta_{2}+i \delta_{1}=\frac{8}{(1+2 i \varepsilon) \cosh (\pi \varepsilon)} \frac{K_{1}+i K_{2}}{E^{*}}\left(\frac{r}{2 \pi}\right)^{1 / 2} r^{i \varepsilon}
\end{aligned}
$$

where $E^{*}=2 \bar{E}_{1} \bar{E}_{2} /\left(\bar{E}_{1}+\bar{E}_{2}\right)$, with $\bar{E}_{i}=E_{i} /\left(1-v_{i}^{2}\right), E_{i}$ and $v_{i}$ being Young's modulus and Poisson's ratio respectively. $K=K_{1}+i K_{2}$ is the (complex) interface Stress Intensity Factor (SIF).

For a crack inside a homogeneous medium, treated in plane strain, the amplitudes of the stress field singularities are commonly defined by stress intensity factors $K_{I}$ and $K_{I I}$ associated with the opening and in-plane sliding deformation, respectively. In such cases, a measure of the mode mixity can be given by angle $\tan ^{-1}\left(K_{I I} / K_{I}\right)$. When the crack propagates at the interface between two different media with different elastic characteristics, the SIF becomes a complex entity, the amplitude of the square-root singular oscillatory stresses, with $K_{1}$ and $K_{2}$ being its real and imaginary parts, respectively. As recalled below, the mode mixity becomes more difficult to define.

We obtain oscillating stress singularities when the $\varepsilon$ parameter is not equal to zero, due to the different elastic properties of the layers, where $\varepsilon$ expresses in plane strain:

$$
\varepsilon=\frac{1}{2 \pi} \ln \left(\frac{1-\beta}{1+\beta}\right), \quad \text { with } \quad \beta=\frac{1}{2} \frac{\mu_{1}\left(1-2 v_{2}\right)-\mu_{2}\left(1-2 v_{1}\right)}{\mu_{1}\left(1-v_{2}\right)+\mu_{2}\left(1-v_{1}\right)}
$$

Here, $\beta$ is the elastic mismatch Dundurs parameter, where $\mu_{i}=E_{i} /\left(2\left(1+v_{i}\right)\right)$. In $(2) \delta_{2}$ and $\delta_{1}$ are respectively the normal and shear opening of the crack flanks, as illustrated by Fig. 10.

In the particular case of the isolated crack of length $2 a$ at the interface of two remotely stressed semi-infinite blocks, the SIF is expressed as [61]:

$$
K=K_{1}+i K_{2}=\left(\sigma_{22}^{\infty}+i \sigma_{12}^{\infty}\right)(1+2 i \varepsilon)(\pi a)^{1 / 2}(2 a)^{-i \varepsilon}
$$

For more complex cases, the expression of $K_{1}$ and $K_{2}$ cannot be obtained analytically. However, we can identify them from finite element simulations in the neighboring region of the crack tip. By inverting expressions (1) or (2) we can define local stress intensity factor values, either from the calculated local stresses ahead of the crack tip, or from the calculated crack opening displacements: 


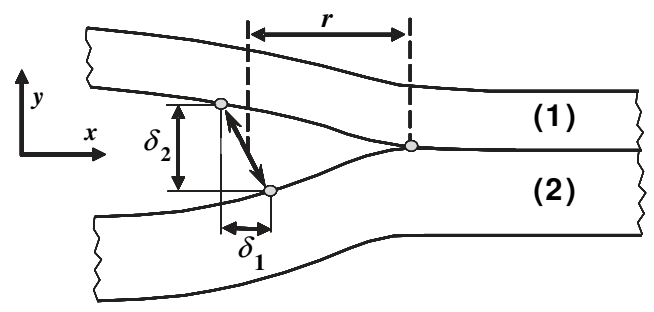

Fig. 10. Node relative displacements at the crack tip.

$$
\begin{aligned}
& \kappa_{1_{\text {disp }}}(r)=\frac{\cosh (\pi \varepsilon) E^{*} \sqrt{2 \pi}}{8 \sqrt{r}}\left[\left(\delta_{2}-2 \varepsilon \delta_{1}\right) \cos (\varepsilon \ln (r))+\left(\delta_{1}+2 \varepsilon \delta_{2}\right) \sin (\varepsilon \ln (r))\right] \\
& \kappa_{2_{\text {disp }}}(r)=\frac{\cosh (\pi \varepsilon) E^{*} \sqrt{2 \pi}}{8 \sqrt{r}}\left[\left(\delta_{1}+2 \varepsilon \delta_{2}\right) \cos (\varepsilon \ln (r))-\left(\delta_{2}-2 \varepsilon \delta_{1}\right) \sin (\varepsilon \ln (r))\right] \\
& \kappa_{1_{\text {stress }}}(r)=\sqrt{2 \pi r}\left(\sigma_{22} \cos (\varepsilon \ln (r))+\sigma_{12} \sin (\varepsilon \ln (r))\right) \\
& \kappa_{2_{\text {stress }}}(r)=\sqrt{2 \pi r}\left(\sigma_{12} \cos (\varepsilon \ln (r))-\sigma_{22} \sin (\varepsilon \ln (r))\right)
\end{aligned}
$$

Due to the oscillating character of the singularity, these quantities depend on the distance to the crack tip and the loading applied.

On the other hand, the definition of a mode mixity angle is standard when the material properties of the layers are the same (the Dundurs parameter $\varepsilon=\beta=0$ ), using the expression $\psi=\tan ^{-1}\left(K_{2} / K_{1}\right)$. Its generalization to the case where $\varepsilon \neq 0$ is made using the following relation $[18,49]$ :

$$
\left.\psi=\tan ^{-1} \frac{\operatorname{Im}\left(K l^{i \varepsilon}\right)}{\operatorname{Re}\left(K l^{i \varepsilon}\right)}\right)
$$

where $l$ is an appropriate characteristic distance whose choice will be discussed below. For a choice of $l$ within the zone of dominance of the K-field, this angle can be expressed either from the opening displacements or the stress field ahead of the crack tip:

$$
\psi_{\text {disp }}=\tan ^{-1}\left(\frac{K_{2}}{K_{1}}\right)+\varepsilon \ln (l)=\tan ^{-1}\left(\frac{\delta_{1}+2 \varepsilon \delta_{2}}{\delta_{2}-2 \varepsilon \delta_{1}}\right)_{r=l} \psi_{\text {stress }}=\tan ^{-1}\left(\frac{\sigma_{12}}{\sigma_{22}}\right)_{r=l}
$$

In our particular case, $\varepsilon=-0.10133$ for the $4 \mathrm{~PB}$ testing condition (Fig. 3 ), with regard to the mechanical features of the bond coat (Material 1) and the topcoat (Material 2). Contrarily, for the I4PB and 4ENF conditions, $\varepsilon=0.10133$.

First of all, we can notice that the mode mixity angle can be positive or negative, between $-90^{\circ}$ and $90^{\circ}$. However, for a given interfacial crack, the surrounding materials have different mechanical properties, and then $\varepsilon$ has a fixed value. This value will limit the range of the mixity angle, i.e., between $\delta_{1}=0$ (normal crack opening) and $\delta_{2}=0$ (pure shearing at the interface). Consequently, if $\delta_{1}=0$, the propagation mode will not be Mode I $\left(0^{\circ}\right)$, but rather near Mode I; likewise, if $\delta_{2}=0$, the propagation will not be pure Mode II due to this material mismatch expressed by the value of $\varepsilon$.

According to various authors, the methods to define the characteristic distance $l$ could optionally be either: the thickness of the thinnest layer [62], a tenth of this thickness [26], the process zone size [63], or an energetically justified distance $[64,65]$. In this latter case, the energy release rate computed from the crack flank displacements is compared to the energy actually released. In this work we have decided to use this energy-based method.

Let us remark that, in order to compare toughness values as a function of the mode mixity (see further on, in Section 4.2), the value of $l$ should be the same, at least for the same multilayered configuration. Another way to fix this value, as suggested in [33], could be to take a wide range of data and to use $l$ to center the data around $\psi=0$.

The expression for the energy release rate in terms of the SIF is classically $[61,66]$ :

$$
G=\frac{1-\beta^{2}}{E^{*}}\left(K_{1}^{2}+K_{2}^{2}\right)
$$

Its evaluation from the finite element simulations can be performed by replacing $K_{1}$ and $K_{2}$ by the local SIF, derived either from the crack opening displacements (5) or from the stresses (6):

$$
g(r)=\frac{1-\beta^{2}}{E^{*}}\left(\kappa_{1}^{2}(r)+\kappa_{2}^{2}(r)\right)
$$

Of course, this quantity varies with the crack tip distance $r$, as shown in Fig. 17, which will be presented in Section 3.2.2. Therefore, the characteristic distance will be chosen at the position $r=l$, where the value of $g(r)$ meets the so-called true elastic energy release rate. This quantity, which has a clear physical meaning, will be defined by a node release technique that gives a good approximation with the fine finite element meshes used in this study. 


\subsection{Finite element analysis}

\subsubsection{Generalities}

For all of our computations, we use the Z-Set finite element software [67], with triangular quadratic elements under generalized plane strain condition. The meshes used to simulate the complete bending specimens are shown in Figs. 11 and 12.

The following finite element analyses, as well as those in Section 3.2.3, were carried out considering the material characteristics indicated in Table 1, which also contains the thicknesses of the various layers. The AM1 substrate is approximated as isotropic. The oxide layer is not represented, due to its very small thickness and its roughness, because that would lead to a much more complex finite element model. Therefore, the crack simulated at the interface between the bond coat and the ceramic topcoat will describe the global debonding very schematically, ignoring the complex geometry and states at the local scale of the oxide.

The zone where the crack tip is modeled is very much refined, with a mesh size of $1 \mu \mathrm{m}$. We do not use quarter-point elements at the crack tip. Nodes in the region of the simulated crack are doubled, and we use contact conditions that enforce the non-penetration of the two flanks.

The finite element calculations are performed in linear elasticity, under the assumption of small strains but large displacements (to solve the contact problems). The approximate linearity of the load-displacement response has been checked under the assumption of large displacements, throughout the experimental loading domain, enabling the results to be summarized under a unit loading force only. In the cases where contact takes place, we have checked that the contact zone at the crack tip is not significantly modified when the loading is changed by a factor of 70 . The contact zones far from the crack tip are also independent from the load.

The elastic energy release rate is obtained by an elementary node release technique, considering that the local element size is sufficiently small $(1 \mu \mathrm{m})$. After comparing several methods (see Section 3.2.2), the one retained is the variation of potential energy when releasing the two first nodes of the quadratic element at the crack tip.

\subsubsection{Analysis of the bending tests}

In the finite element analysis presented in this section, the effects of residual stresses are neglected. Their influence will be shown and discussed in Section 4.3. Some details are now given concerning the boundary and loading conditions applied in the bending test calculations.

The nodes in contact with the rollers on the lower surface of the specimen are fixed in the $y$ direction. Similarly, the loading is applied as two equal point forces on the nodes associated with the inner loading points. The stress concentration

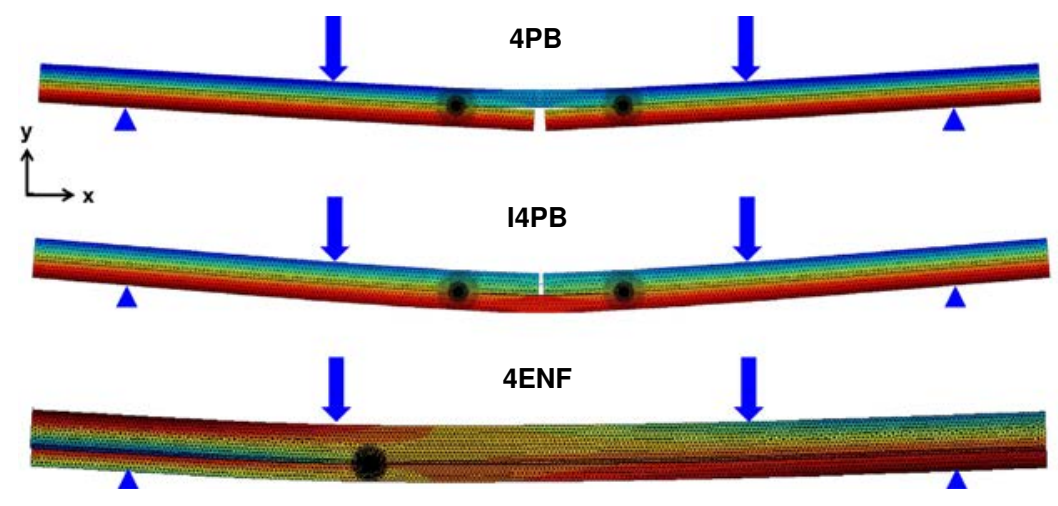

Fig. 11. General overview of the meshes used in the finite element simulation to compute the 4PB, I4PB and 4ENF tests. The amplification factors for displacements are 10, 20 and 70 for $4 \mathrm{~PB}$, I4PB and 4ENF respectively. The color maps correspond to the horizontal displacement. (For interpretation of the references to color in this figure legend, the reader is referred to the web version of this article.)

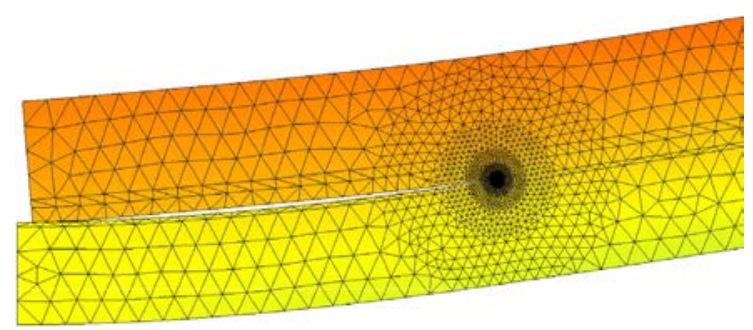

Fig. 12. Example of the mesh used in the crack tip zone in the finite element simulation of the I4PB bending test (displacement amplification by 40 ). 
occurring at these points does not present any difficulty, given the thickness of the various layers and the significant distance between these loading points and the crack tip. Sliding at these points has also been neglected.

The symmetry in case of $4 \mathrm{~PB}$ and I4PB has been enforced, meshing only one half of the specimen. For example, for the $5 \mathrm{~mm}$ half-crack length $a$, the mesh contains 6974 elements and 14,353 nodes (whereas the number of nodes is 3690 when linear elements are considered). In the case of the $4 \mathrm{ENF}$ test, it is necessary to mesh the complete specimen. The mesh consists of 9962 elements and 20,749 nodes (whereas the number of nodes is 5394 when linear elements are considered). The horizontal displacement of the top node at the left end is zero.

It has been shown that the mesh refinement of the substrate in the area most subjected to bending (center of the specimen) does not impact the results at the crack tip for an element size between $10 \mu \mathrm{m}$ and $300 \mu \mathrm{m}$. We have finally chosen an element size of $250 \mu \mathrm{m}$ for this area.

The elastic energy release rate has been calculated by several methods, whose results were systematically compared:

- the perturbation method proposed by Parks [68], with various perturbations (from $10^{-4}$ to $10^{-10} \mu \mathrm{m}$ ). Fig. 13 shows that, for quadratic elements of $1 \mu \mathrm{m}$ size, perturbations of $10^{-5}$ to $10^{-3} \mu \mathrm{m}$ deliver approximately constant results. The figure also shows the various results obtained with $1 \mu \mathrm{m}$ size linear elements. Finally, this method is used with quadratic elements and a $10^{-5} \mu \mathrm{m}$ perturbation;

- the variation of potential energy when releasing the two nodes of the first quadratic element at the crack tip. For bending configurations, we add the work done by the external load (at its point of application) and the internal energy variation. For applications without an external load (edging delamination and buckling configurations, presented in the next section), it is directly the internal elastic energy variation;

- the virtual crack closure technique, VCCT [69], in which the work induced during the release of the two nodes of the first element at the crack tip is calculated by the product of internal reactions (before) and opening displacements (after).

Table 2 reports the calculated energy release rates with the various methods for the three bending configurations. Finally, the simplest method retained is the variation of potential energy when releasing first nodes at the crack tip.

Fig. 14 shows the change in the energy release rate (under an external force of $1 \mathrm{~N} . \mathrm{mm}^{-1}$ ) for each test, as a function of the crack length $a$ (or half-crack length). In every case, a significant portion of the crack length enables steady state propagation.

In $4 \mathrm{~PB}$, the energy release rate appears as constant for a very small crack length, until the crack tip attains the position of the inner support. Then, it decreases very rapidly. In this steady state case, an analytical solution can also be used, based on finite fracture mechanics analysis, considering the states and the elastic energies stored before and after separation of the layers (we can see such solutions in the works of Hutchinson [18], Howard [70], and Martin [20]). Using the pure bending approximation of plates (under generalized plane strain conditions) we obtained $4.8956 \mathrm{~J} . \mathrm{m}^{-2}$, a difference of less than $0.1 \%$ compared to the $4.9000 \mathrm{~J} \cdot \mathrm{m}^{-2}$ value yielded by the finite element analysis for the crack with $5 \mathrm{~mm}$ length (as shown in Figs. 13 and $14 a)$.

This solution, similar to that obtained by Zhang et al. [71], generalizes the classical analytical solutions (like those available in the work of Suo \& Hutchinson [26], or in that of Howard et al. [70]) for any situation, whatever the number of layers considered, including residual stresses (induced, for instance, by thermal mismatches). However, in this section, we neglect the residual stresses. This analytical solution takes into account elongations and deflections in the two in-plane directions, but can be restricted to the cases of generalized plane strain or plane strain. This has been published in another context, as an appendix, in [72]. The strains yielded by this solution, along the thickness of each layer, can easily be integrated in close form

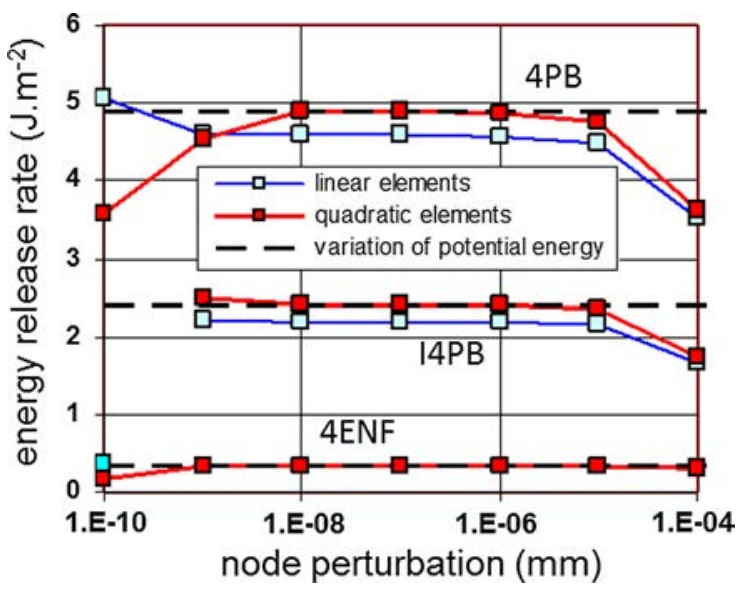

Fig. 13. Convergence of the Parks perturbation method for determining the energy release rate in the 3 bending tests. The dashed line indicates the solution from the variation of potential energy by the node release technique. 

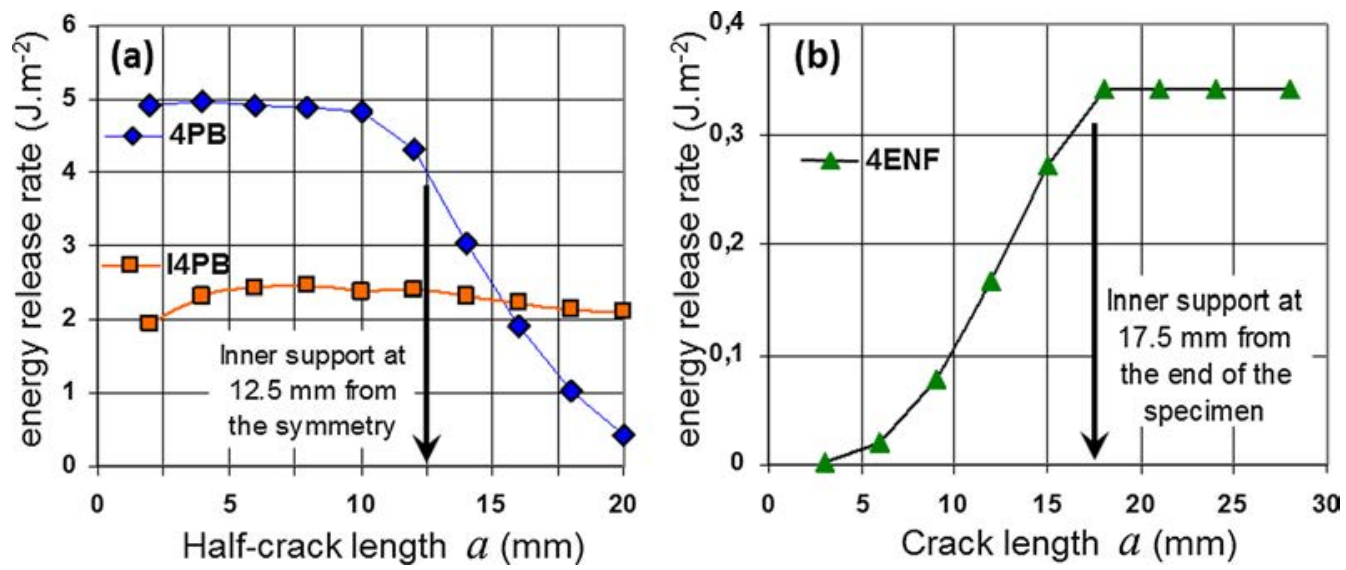

Fig. 14. Variation of the energy release rate with the crack length for the three bending tests (a) 4PB and I4PB - (b) 4ENF.

to obtain the elastically stored strain energies before and after the complete interfacial separation between the upper and lower parts of the multilayered plate.

The region of constant energy release rate is slightly larger in the I4PB situation (from 4 to 14 mm). We observe both a much lower energy release rate compared to the 4PB case, and its slower decrease after the position of the inner support. These lower values for the same external bending moment are clearly due to the contact point near the center of the specimen, increasing the global stiffness of the system.

Contrarily, under the 4ENF testing condition, the energy release rate increases from a short crack at the specimen external end (with a zero value for a crack tip near the external support) to a constant value after a crack tip position just above the inner support. Moreover, due to the thicker steel plate ( $2 \mathrm{~mm}$ instead of $1 \mathrm{~mm}$ in the I4PB), the energy release rate under stationary conditions is much lower than in the previous case.

We now use the method of determining the mode mixity angle, which was explained in Section 3.1. By extracting the crack opening displacements and the stress fields forward of the tip, and using Eqs. (5) or (6), and then using Eq. (10), we obtain from these two numerical solutions the evaluations of the energy release rate as functions of the distance to the crack tip.

Still considering a load of $1 \mathrm{~N} . \mathrm{mm}^{-1}$ (defined for the unit depth of the rectangular plate specimen), we plot these results in Fig. 15. The horizontal dashed lines indicate the true elastic energy release rate, as obtained before by the node release technique. It can be observed that the opening displacement based evaluation intersects for the three cases with the actual energy release rate. Contrarily, the stress-based solution seems to converge towards the true value but does not intersect with it in the case of $4 \mathrm{~PB}$. In the other cases, the intersection occurs for very short distances (compared to the $1 \mu \mathrm{m}$ size of the finite elements). For this reason, we define the characteristic distance from the opening displacement solution.

Likewise, the obtained characteristic distances $l$ are around 5.4, 10.2, and $74.1 \mu \mathrm{m}$, for 4PB, I4PB and 4ENF testing conditions respectively.

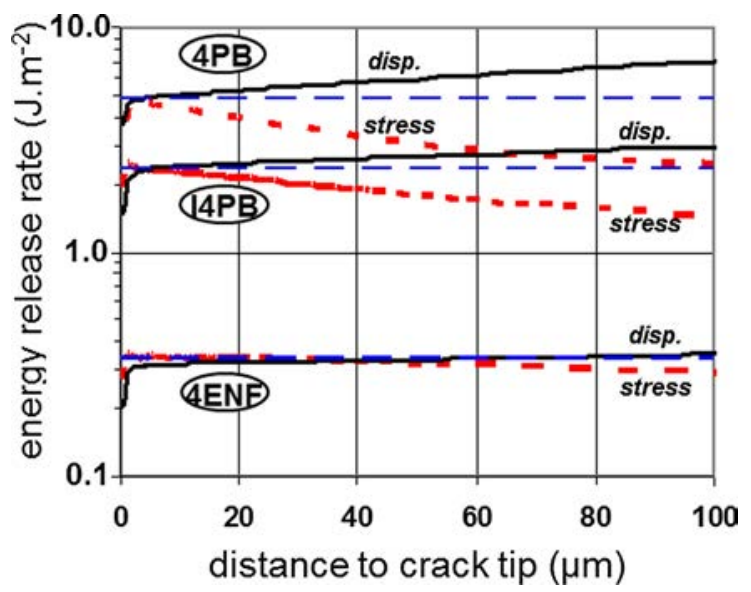

Fig. 15. Variation of the energy release rate for the three bending tests, regarding the crack tip distance $r$. 
The variations of the mixity angle with the distance to the crack tip are plotted in Fig. 16 for the three bending tests considered, as determined by Relation (8).

From the characteristic distances selected just above, we obtain the mode mixity angles. These values are indicated in Table 3 for the two determination methods (displacement and stress based solutions). It can be observed that these two determinations provide quite similar values. Despite the limited differences, the final mode mixity angles retained in this work are those given by the opening displacement solution, which appear to be less sensitive to the characteristic distance.

Then, we can notice that, in the direct four point bending situation (4PB), in which the steel stiffener and ceramic topcoat are at the bottom (see Fig. 3), the crack is more or less under opening conditions, so the mode mixity is quite low. Conversely, in the inverted 4-point bending (I4PB), the interface and the crack tip are loaded differently, because of the contact near the center of the specimen, inducing a larger component of Mode II relative to Mode I.

Let us now discuss the contact and crack closure effects observed in the FE calculations for the three test configurations, and the validity of the approach used in this work to extract the mode mixity angle:

- in the 4PB specimen, obviously, the crack is open everywhere;

- in the I4PB, there is a contact point near the center of the specimen, as shown in Fig. 12. At the crack tip, the crack is closed over $2 \mu \mathrm{m}$ only, for the whole domain of applied loads in the experiments. Therefore, the use of the analytical solutions, (5) and (6), is considered to be acceptable;

- in the 4ENF specimen, there is a large contact zone (closure of the crack) at the position of the outer loading point (near $5 \mathrm{~mm}$ ). However, the crack is also closed near the crack tip, over $90 \mu \mathrm{m}$. These two contact zones are totally independent from the applied load between 1 and $70 \mathrm{~N} \cdot \mathrm{mm}^{-1}$ (for the unit depth), corresponding to the maximum experimental load. In that case, the analytical solutions used, (5) and (6), are no longer acceptable. Therefore, the characteristic distance determined $(76.2 \mu \mathrm{m})$ appears questionable. However, as $\delta_{2}=0$ all along this zone, Eq. (8a) gives the mode mixity angle by $\psi=\tan ^{-1}(-1 /(2 \varepsilon))$, independently from the distance to the crack tip. Even if questionable, as being the limit value given by an approximate solution in the present case, we consider that such a value may be retained for the exploitation made in this paper.

Let us remark that research work has been carried out in the past (see Comminou [73,74]) to obtain analytical solutions for cases where closure takes place at the crack tip. However, these quite elaborate solutions are not available in closed form. Their application was considered to be beyond the scope of this experimental work.

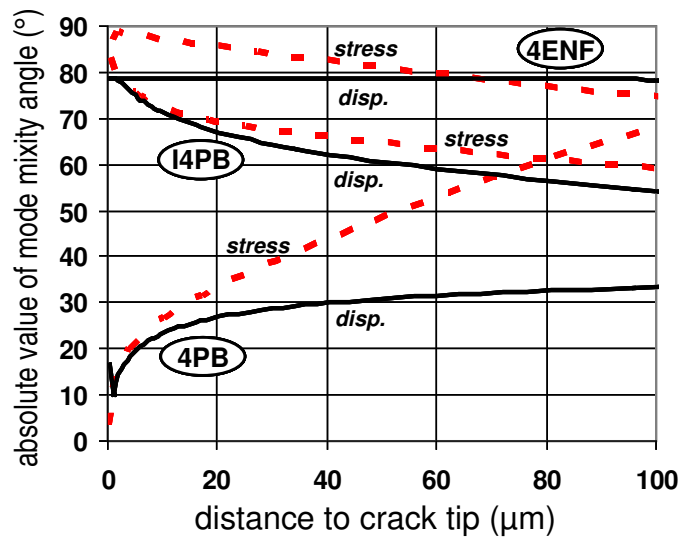

Fig. 16. Variation of the mode mixity angle, with regard to the crack tip distance $r$.

Table 3

Energy release rate and mode mixity angle values, for each bending test, under an applied load of $1 \mathrm{~N}^{\mathrm{m}} \mathrm{mm}^{-1}$.The Top Coat (TC) has the same elastic characteristics than the BondCoat (BC).

\begin{tabular}{|c|c|c|c|c|c|}
\hline & $\varepsilon$ & Energy release rate $\left(\mathrm{J} \cdot \mathrm{m}^{-2}\right)$ & Distance $l(\mu \mathrm{m})$ & $\psi_{\text {dep }}\left({ }^{\circ}\right)$ & $\psi_{\text {sig }}\left(^{\circ}\right)$ \\
\hline $4 \mathrm{~PB}$ & -0.1013 & 4.900 & 5.38 & -19.97 & -21.84 \\
\hline I4PB & 0.1013 & 2.415 & 10.23 & -71.13 & -72.11 \\
\hline 4ENF & 0.1013 & 0.339 & 74.11 & -78.54 & -77.49 \\
\hline 4PB, TC replaced by $B C$ & 0. & 4.899 & 4.88 & -28.79 & -30.47 \\
\hline 4PB homogeneous & 0. & 5.557 & 7.50 & -40.05 & -40.82 \\
\hline I4PB homogeneous & 0. & 2.613 & 15.03 & -50.06 & -50.78 \\
\hline 4ENF homogeneous & 0. & 0.373 & 28.83 & -74.05 & -74.70 \\
\hline
\end{tabular}


It should also be noted that all test conditions present negative mixity angles. This results from both the sign of the misfit parameter $\varepsilon$ for the various configurations, and also from the sign of the moment applied by the mechanical system (see Figs. 3-5). Usually, the mixity of the 4PB test is given as a positive angle. This is because, in those cases, the moment is opposite (see, for example, Fig. 4A of Ref. [17]).

Another remark is that the mixity angle for $4 \mathrm{~PB}\left(\right.$ about $20^{\circ}$ ) is significantly smaller than the values commonly reported in the literature $\left(30-45^{\circ}\right)$. This is partly due to the elastic misfit between the materials adjacent to the cracked interface. We have made additional calculations with exactly the same FE model, but the same material in the two adjacent layers (we used the bond coat characteristics). In this case we have found, always by the same method, a mixity angle of about $30^{\circ}$ (see Table 3). The second reason is the difference between the other materials, giving rise to different bending inertia between the upper and lower parts (respectively the stiffener and the single crystal). Using the same material characteristics for all of the layers (the bond coat material), the value is $\psi=40^{\circ}$, which fits well with the value found in [17]. We have also treated the homogeneous case for I4PB (Fig. 4) and 4ENF (Fig. 5) specimens, leading to mixity angles near $-50^{\circ}$ and $-74^{\circ}$ respectively.

\subsubsection{Analysis of edge delamination and buckling configurations}

We now consider the schematic turbine blade spalling configurations that have been presented and discussed in Section 2.1. The numerical analyses are done using finite elements, using similar meshes as in the bending configurations, but with a smaller size of elements near the crack tip $(0.1 \mu \mathrm{m})$. The geometry near the crack tip is shown in Figs. 17 and 18. In the edge delamination case, the mesh contains 20,580 elements and 42,053 nodes. For the buckling case, it contains 41,720 elements and 84,426 nodes.

The geometry considered involves only 3 layers, the ceramic topcoat, the bond coat and the substrate. The thermoelastic material characteristics, as well as the thicknesses, are the same as previously (see Table 1).

These configurations involve only internal loads, produced by residual stresses, essentially thermal stresses induced by the thermal expansion misfits. The initial stress-free state is considered to be at the maximum temperature of $1100{ }^{\circ} \mathrm{C}$,

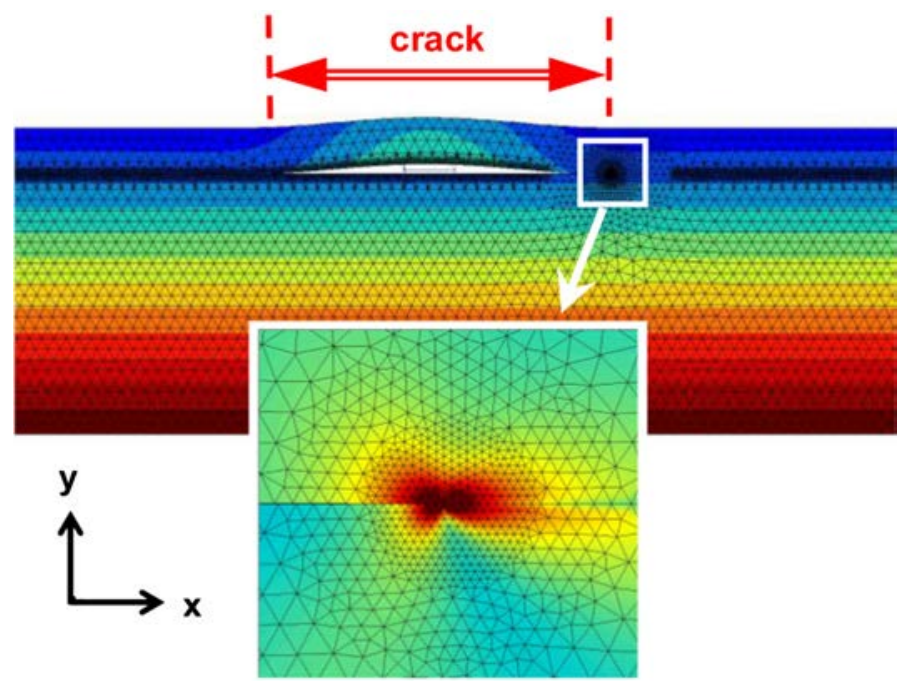

Fig. 17. General overview of the meshes used in the finite element simulation to compute the buckling configuration. The vertical displacement is plotted, from 0 at the bottom to $-0.015 \mathrm{~mm}$ at the top (between -0.01 and $-0.0125 \mathrm{~mm}$ in the central part of the buckle). The insert shows the local mesh ( $0.1 \mu \mathrm{m}$ ) and the Von Mises field, between $125 \mathrm{MPa}$ (light blue) and $600 \mathrm{MPa}$, near the crack tip (brown). (For interpretation of the references to color in this figure legend, the reader is referred to the web version of this article.)

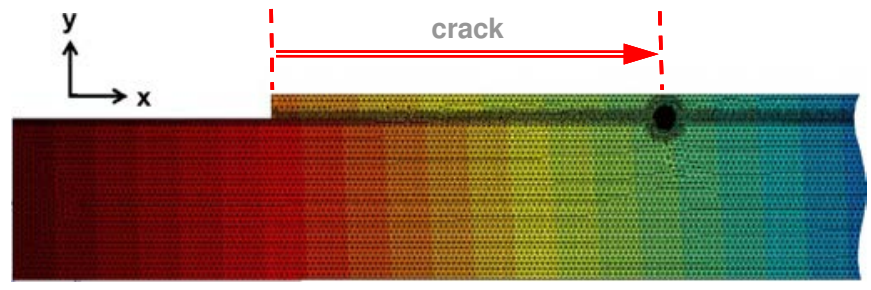

Fig. 18. General overview of the meshes used in the finite element simulation to compute the edge delamination case. The horizontal displacement field is represented in the figure, from zero on the left to about $0.09 \mathrm{~mm}$ on the right. 
and the loading corresponds to thermal cooling of the system from 1100 to $25^{\circ} \mathrm{C}$, which is assumed to be representative of a blade cooling down. In these calculations, the elastic energy release rate $G$ is approximated by the variation of potential energy when the crack tip nodes are released.

In the case of edge delamination, the length of the considered specimen is $32 \mathrm{~mm}$, though the zone with the topcoat is $30 \mathrm{~mm}$ long. Fig. 19 shows that, except for the first $2 \mathrm{~mm}$ and at the very end, the energy release rate is almost constant along the crack path, thus the propagation can be considered as in steady state.

In the second case of "buckling", the ratio between the initial crack opening $\delta_{0}$ and the crack length is fixed at a given value $\delta_{0} / a=0.025$. Under such conditions, Fig. 20a demonstrates that when the pre-buckle crack length increases the energy release rate increases also. This means that it becomes increasingly easy for the crack to propagate when the buckle becomes larger. Considering a cooling period, from the maximum temperature (the stress-free state) to room temperature, the available energy to be released increases more rapidly for a larger crack length, and will reach its critical value earlier.

The method to compute the mode mixity angle, as explained in Section 3, can be applied to determine whether the crack propagates mainly in Mode I or in Mode II. For the "edge delamination" configuration, both the obtained characteristic distance and the mixity angle are approximately constant all over the region where the energy release rate is constant. For the "buckling" case, not knowing the appropriate buckle diameter to use, we applied this method for all of the different lengths of pre-buckle crack considered in our computations. Although the characteristic distance varies significantly with the buckle size, as shown in Fig. 20b, the mode mixity angle only varies slightly (from -63.06 to $-76.08^{\circ}$ ).

Table 4 gives the retained values of the energy release rate under such cooling conditions. As explained in Section 3, the corresponding characteristic distance is the crack tip distance, where the energy release rate given by the crack opening displacements is equal to that obtained numerically by the node release technique. The mixity angles derived at the characteristic distance are then, respectively, $-78.54^{\circ}$ and $-64^{\circ}$ for the edging and buckling cases.

Let us note that, for the edge delamination case, $-78.54^{\circ}$ corresponds to a pure Mode II in this case, where the Dundurs parameter $\varepsilon=0.10133$ and the crack is totally closed near the crack tip, in which case $\psi=\tan ^{-1}(-1 /(2 \varepsilon))=-78.54^{\circ}$. Even

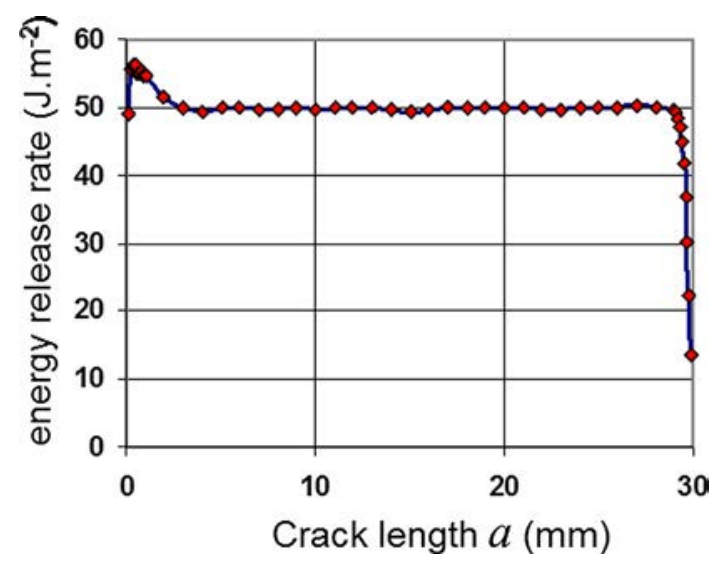

Fig. 19. Energy release rate versus the crack length (edge delamination condition).
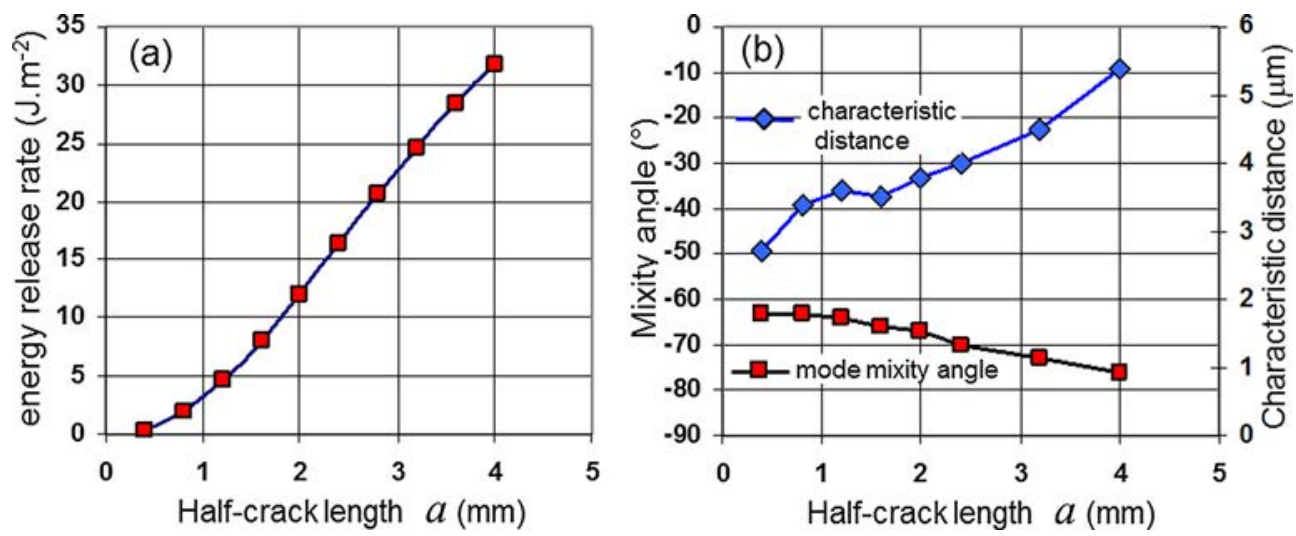

Fig. 20. Buckling case: (a) energy release rate, depending on the crack length (opening proportional to crack length) (b) Variations in the mixity mode angle and characteristic distance with the crack length (buckle size). 
Table 4

Values for the two propagation scenarios, using the mixity angle determination method.

\begin{tabular}{lllll}
\hline Case & Crack length $(\mathrm{mm})$ & Energy release rate $\left(\mathrm{J} \cdot \mathrm{m}^{-2}\right)$ & Distance $(\mu \mathrm{m})$ & Mixity angle by displacements $\left(^{\circ}\right)$ \\
\hline Edge delamination & 4.0 & 49.723 & 56.0 & -78.54 \\
Buckling & 1.2 & 4.606 & 3.6 & -64.02 \\
\hline
\end{tabular}

though the used asymptotic solution of Section 3.1 is no longer valid in this case, we accept this approximation which, at least, is consistent with the treatment for the 4ENF tests. For the "buckling" case, the asymptotic solution is assumed to be consistent, since we checked that the closure of the cracks takes place over a distance of only a few micrometers. For our particular multilayered system, we can conclude from the mixity angle values obtained that, under blade loading conditions, the interface crack is very likely to propagate near Mode II.

Concerning the edge delamination configuration, it may be of some interest to discuss the limitations of the generalized plane strain approximation that we used when calculating the energy release rate by finite elements.

This approximation appears to be too greatly constraining when considering separately the zones of the plate on the right hand side and the left hand side of the crack tip (for a crack extending from the left to the right). On the right, sufficiently far from the crack tip, the layers above and below the non-cracked interface can be considered with the same transverse strain $\varepsilon_{33}^{(0)}$. Contrarily, when the interface is broken far from the crack tip on the left, the specimen is separated into two independent multilayer plates, which may behave under the generalized plane strain approximation, but with two different transverse strains $\varepsilon_{33}^{(1)}$ and $\varepsilon_{33}^{(2)}$.

This is exactly what we obtain when using the analytical solution based on the plate bending theory and on a finite fracture mechanics analysis. It considers the states and the elastic energies stored before and after the separation of the layers. This method was briefly described at the beginning of Section 3.2.2 and in [72]. In this material and geometrical configuration, under the generalized plane strain assumption, the analytical solution yields an energy release rate of $90.8506 \mathrm{~J} . \mathrm{m}^{-2}$, much above the total energy released with the finite element results shown in Fig. 19, in which the integration of $G(a)$ along the total crack path is $49.57 \mathrm{~J} \cdot \mathrm{m}^{-2}$.

On the other side, if we use the analytical solution and constrain the transverse strain to be the same after the separation induced by the crack propagation as it was before in the complete unbroken multilayered plate, we also recover exactly the average finite element result above, i.e., $49.688 \mathrm{~J} \cdot \mathrm{m}^{-2}$. To conclude this discussion, it is clear that a correct solution would be the 3D finite element analysis of this configuration.

\section{Test results and discussion}

The three kinds of bending tests have been performed on a number of plate-shaped TBC specimens, under 'as-deposited' conditions or after various numbers of $1 \mathrm{~h}$ thermal cycles, with a holding temperature of 1070,1100 or $1150{ }^{\circ} \mathrm{C}$. Given that several batches of deposited TBC samples were tested, there is a significant randomness in the results. However, as will be shown below in Figs. 21-23, it is possible to extract the main trends relative to the effects of the mode mixity and the prior aging.

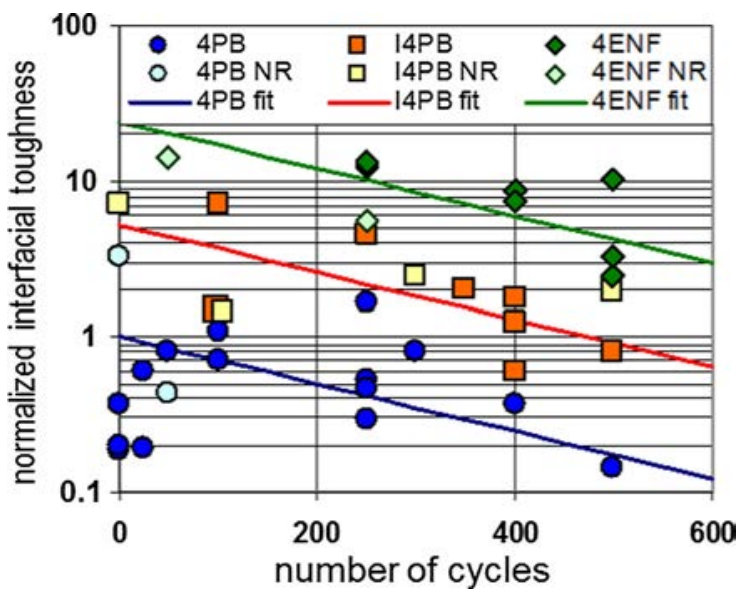

Fig. 21. Decrease in the interfacial fracture toughness with the cyclic thermal aging (experiments and their exponential fitting). 


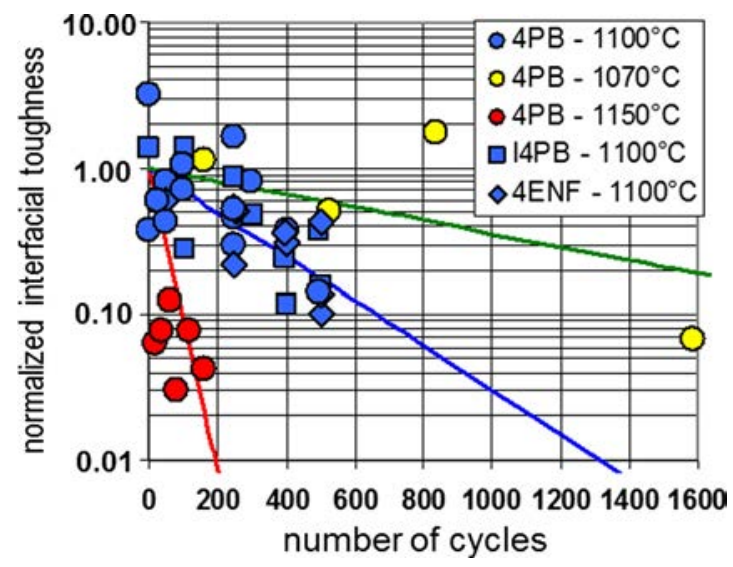

Fig. 22. Effect of the holding temperature on the interfacial toughness evolution.

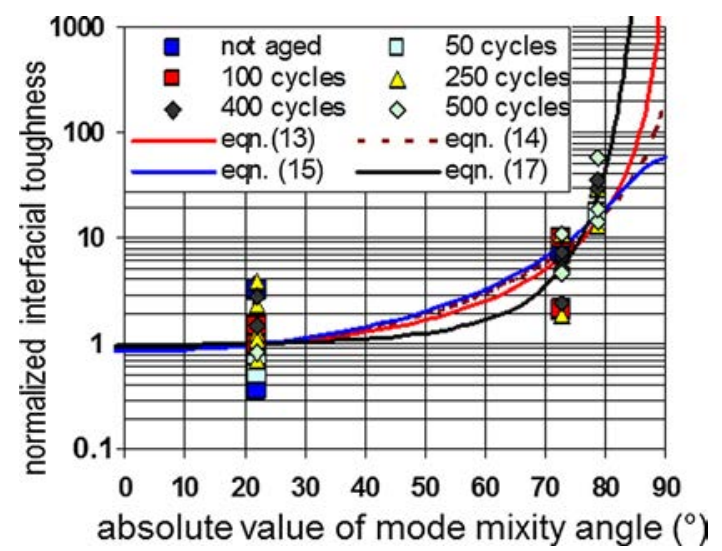

Fig. 23. Variation with the mode mixity of the normalized interfacial toughness (experimental results and some fitting curves).

\subsection{Ageing dependence of the toughness}

Except for those tested in the 'as-received' condition, the samples undergo furnace cycling tests of $1 \mathrm{~h}$ at $1100{ }^{\circ} \mathrm{C}$, respectively up to $50,100,250,400$ and 500 cycles. We then measure the residual toughness of TBC, using either 4PB, I4PB or 4ENF tests. The results of the whole experimental set are shown in Fig. 21 as the toughness, normalized by its value for the 4PB specimen in the 'as-received' state (obtained by the fitting procedure indicated below). The plain symbols correspond to specimens in which the interface crack has effectively propagated with a stable appearance. The toughness values for interrupted tests due to the earlier debonding of the stiffener are indicated by NR in the caption. In such cases, the actual tough-

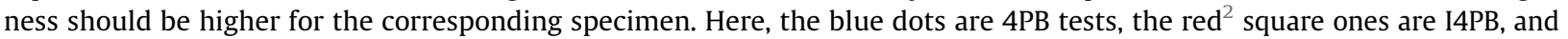
the green diamonds are 4ENF.

A general decreasing trend of the interface toughness with the applied number of cycles can be noted in Fig. 21 . Globally, we can consider that the toughness decrease versus the thermal cycling is independent from the test type: damage occurring inside the furnace does not depend of the ongoing test. We can henceforth propose the following expression to fit this decrease, assuming in our case a decreasing exponential function of a damage parameter $D$, which itself should increase linearly with the number of cycles:

$$
G_{c}=G_{0} \exp \left(-\alpha_{0} D\right)=G_{0} \exp (-\alpha N)
$$

where $\alpha$ is is the same for the three experimental slopes. Moreover, the shift between the three curves depends on the mixity angle (see Section 4.2) It means that $G_{0}$, the value of $G_{c}$ at $N=0$ for the three sets of experiments, is defined also from the fitting chosen in the next Section 2.2. It is worthy to note that, for 4PB tests, the trend for experimental results at the beginning of aging (before $100 \mathrm{~h}$ ), is an increase in the toughness. This fact, already observed [52] but difficult to understand, is not

\footnotetext{
${ }^{2}$ For interpretation of color in Fig. 21, the reader is referred to the web version of this article.
} 
taken into account in our fitting procedure (indicated below). It explains the higher value of the initial toughness (normalized to 1 in the figure) compared to those experimental points in the undamaged state.

4-point bending tests have also been carried out after different aging times at $1070^{\circ} \mathrm{C}$ and $1150{ }^{\circ} \mathrm{C}$, in order to characterize the influence of temperature on the damage process at the interface. Fig. 22 shows the interfacial toughness obtained as a function of the aging number of cycles. The tests on $4 \mathrm{~PB}, \mathrm{I} \mathrm{IPB}$ and $4 \mathrm{ENF}$ are independently normalized by the corresponding values for the as-received state, as obtained by the exponential fitting in Fig. 21.

It can be observed that the higher the holding temperature is, the faster the decrease in the interfacial toughness is. Thus, this temperature dependence has been described by an Arrhenius law and the solid lines correspond to the following expression:

$$
\alpha_{0} D=\alpha N=A t \exp \left(\frac{-Q_{D}}{R T}\right)
$$

in which the damage evolution is assumed to be linear with the time $t$ at the holding temperature $T$ (expressed in $\mathrm{K}$ ). $A$ is a damage parameter, $Q_{D}$ is the activation energy of the damaging process and $R$ is the ideal gas constant. The experimental data fitting procedure is briefly described at the end of Section 4.2.

\subsection{Mixity dependence of the toughness}

Knowing the measured toughness for each bending test, we can determine its dependence regarding the mode mixity. In the literature [18], there are various possible expressions used to describe this dependence:

$$
\begin{aligned}
& G_{c}=G_{I c}\left(1+(1-\lambda) \tan ^{2}(\psi)\right) \\
& G_{c}=G_{I c}\left(1+\tan ^{2}(\psi(1-\lambda))\right) \\
& G_{c}=\frac{G_{I c}}{1+(\lambda-1) \sin ^{2}(\psi)}
\end{aligned}
$$

in which $G_{I c}$ is the interfacial fracture toughness for the 'as-received' specimens in the pure crack opening mode (Mode I). $\lambda$ is an interfacial parameter, depending on both the materials of the crack flanks and the interfacial roughness. It is well accepted that interfacial fracture toughness $G_{c}$ can be asymmetric in $\psi$ [17]. However, regarding the convention used in this paper (same convention as in [18]), we assume, as a good approximation, the evolution of $G_{c}$ to be symmetric in $\psi$.

The above phenomenological relations should be based on mixity angles calculated for the same characteristic length $L$. From the values $\psi_{0}$ obtained in Section 3.2.2 for each test condition, we transform the mixity angle into:

$$
\psi=\psi_{0}+\varepsilon \ln (L / l)
$$

where $l$ is the characteristic length obtained when determining the mixity angle (reported in Table 3). For the 4ENF tests, since the mixity angle was independent from this length, we do not change its value. Choosing $L=7.80 \mathrm{~mm}$ as the average between the lengths determined for $4 \mathrm{~PB}$ and $\mathrm{I} 4 \mathrm{~PB}$ specimens, we finally obtain: $\psi 4 \mathrm{~PB}=-22.13^{\circ}, \psi_{\mathrm{I} 4 \mathrm{~PB}}=-72.71^{\circ}$, $\psi_{4 \mathrm{ENF}}=-78.54^{\circ}$.

Fig. 23 presents the experimental results of the interface toughness after several aging processes, as a function of the absolute value of the mixity angle just defined beforehand. All of the available experimental data have been normalized for each aging state $\left(50,100,250,400\right.$ and 500 cycles at $\left.1100{ }^{\circ} \mathrm{C}\right)$ by the corresponding attributed value for the 4-point bending test, through the fitting relation $G_{c}=G_{0} e^{-\alpha N}$, where $G_{0}$ corresponds to the interfacial toughness for the 4-point bending test on the as received material.

As shown in Fig. 23, the three previous equations do not fit our experimental results sufficiently well, whichever the value taken for $\lambda$. In fact, the best fit was obtained for each equation for different low values of $\lambda$ ( $\lambda=0.4$ for Eq. (13), $\lambda=0.04$ for Eq. (14), $\lambda=0.015$ for Eq. (15), but was unable to describe the higher non-linearity in the mode mixity angle dependency. Henceforth, we propose a new expression for the mixity dependence of the interfacial toughness. The following one (black curve in Fig. 23) seems to give a sufficiently good fit for our experimental results (especially with the values $n=4$, and $\lambda=0.797)$

$$
G_{c}=G_{I c}\left(1+\frac{1-\lambda}{n} \tan ^{2}(\psi)\right)^{n}
$$

Let us remark that the best fit for the experiments is obtained by simultaneously determining the value of $G_{I c}$, the parameters $\lambda$ and $n$ above (from the fitting in Fig. 23), and the slope $\alpha=0.0035$ of the exponential toughness decrease with the number of cycles (Fig. 21). Concerning the activation energy of the damaging process in Relation (12), after determining $\alpha$ from the fitting at $1100{ }^{\circ} \mathrm{C}$, the few additional results at 1070 and $1150^{\circ} \mathrm{C}$ give $Q_{D}=620 \mathrm{~kJ} \cdot \mathrm{mol}^{-1}$ as a good compromise. Moreover, given that the total time at the maximum temperature is $1 \mathrm{~h}$, from $\alpha=0.0035$ at $1100^{\circ} \mathrm{C}$, we obtain $A=3.74510^{17} \mathrm{~s}^{-1}$. 


\subsection{An approach based on an arbitrary characteristic length}

As shown above, we had some difficulties in defining the characteristic distance from which the mode mixity can be determined. The dependency between the mode mixity angle and the interface toughness is approximated by a phenomenological relation, with parameters $G_{I c}, \lambda$, and $n$. We try here a significantly different approach, proposed by Banks-Sills et al. [33,34], in which the relation between the mode mixity and the toughness has a fixed form, but the characteristic length $L$ and the Mode 1 toughness $G_{1 c}$ are the only material dependent parameters.

The first step is to define a normalized SIF:

$$
\hat{K}=K \hat{L}^{i \varepsilon}
$$

where the classical SIF $K=K_{1}+i K_{2}$, the units of which are $F L^{-i \varepsilon} / L^{3 / 2}$, is replaced by $\hat{K}=\hat{K}_{1}+i \hat{K}_{2}$, which has the usual units of SIF, namely $F / L^{3 / 2}$. The mixity angle $\psi$ is then expressed as:

$$
\psi=\tan ^{-1}\left(\frac{\operatorname{Im}(\hat{K})}{\operatorname{Re}(\hat{K})}\right)=\tan ^{-1}\left(\frac{\hat{K}_{2}}{\hat{K}_{1}}\right)
$$

Though the energy release rate in (9) can now be written as:

$$
G=\frac{1-\beta^{2}}{E^{*}}\left(\hat{K}_{1}^{2}+\hat{K}_{2}^{2}\right)
$$

The second step is to postulate the critical energy release rate (or toughness) with the same form:

$$
G_{c}=\frac{1-\beta^{2}}{E^{*}}\left(\hat{K}_{1 c}^{2}+\hat{K}_{2 c}^{2}\right)=\frac{1-\beta^{2}}{E^{*}} \hat{K}_{1 c}^{2}\left(1+\left(\frac{\hat{K}_{2 c}}{\hat{K}_{1 c}}\right)^{2}\right)
$$

that is, with (19):

$$
G_{c}=G_{1 c}\left(1+\tan ^{2}(\psi)\right)
$$

where $G_{1 c}=\left(1-\beta^{2}\right) \hat{K}_{1 c}^{2} / E^{*}$ is now a constant, depending on the materials above and below the interface. Eq. (22) now plays exactly the same role as Relations (13) to (15) and (17) in Section 4.2. The other material parameter to be identified is the characteristic length $\hat{L}$ that lies behind the normalized SIF and the mixity angle.

In our case, for each candidate choice of the length $\hat{L}$, we determine $\hat{K}_{1}(r)$ and $\hat{K}_{2}(r)$ by (18) from the so-called local SIFs $\kappa_{1}(r)$ and $\kappa_{2}(r)$ determined from the FE results, either by (5) from the opening displacements or by (6) from the stresses.

The retained mode mixity angle is then given by (19), applied at the distance $\hat{L}$ to the crack tip. Fig. 24 shows the variations in the absolute value of the mixity angle as a function of the chosen length $\hat{L}$, for the three testing conditions. Using the same normalized experimental data as before (in Fig. 23) for the toughness, we have adjusted $\hat{L}=22.8 \mu \mathrm{m}$ for the best fit of these data by Eq. (22), reported in Fig. 25 . The corresponding mode mixity angles are $-26.94^{\circ},-66.52^{\circ}$ and $-78.54^{\circ}$ for the $4 \mathrm{~PB}, \mathrm{I} 4 \mathrm{~PB}$ and $4 \mathrm{ENF}$ tests respectively. The curve representing Eq. (22) is normalized to take the value 1 for the mixity angle of 4PB. It shows that this method gives an acceptable fit, compared with that achieved by Eq. (17) in Fig. 23, without introducing the fitting parameters $\lambda$, and $n$, only the characteristic length $\hat{L}$ being adjusted.

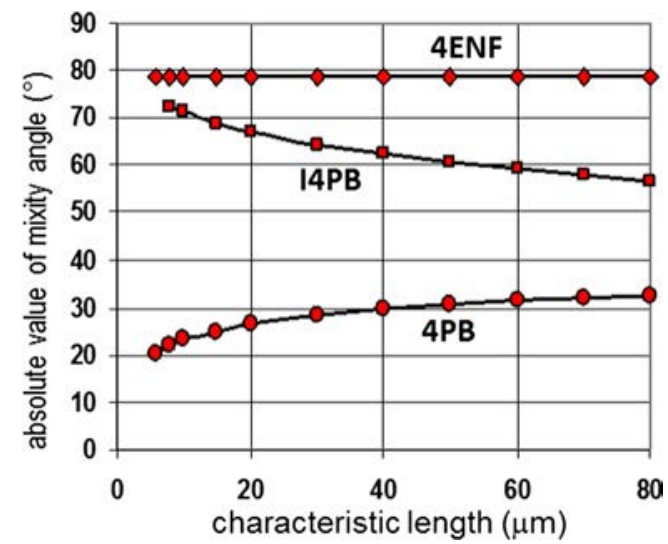

Fig. 24. Absolute value of the mode mixity angle as a function of the chosen characteristic length. 


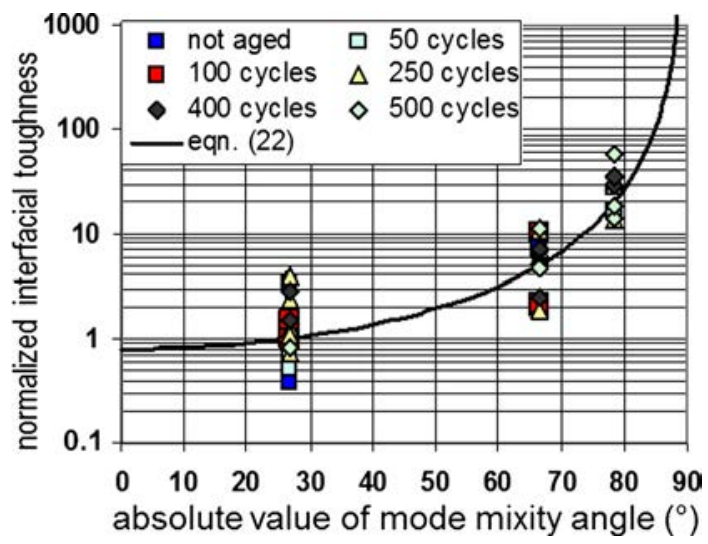

Fig. 25. Toughness dependency on the mode mixity angle with the approach using the characteristic length as a fitting parameter.

\subsection{Taking into account residual stresses}

In the above analysis, the measured energy release rate is not exactly the intrinsic critical energy release rate of the interface between the ceramic topcoat and the substrate, but rather only the external energy, induced by the bending moment applied to the system at room temperature, in order to propagate the pre-existing crack. However, significant residual stresses are often present in thermal barrier coating systems. They can arise during manufacturing processes or under service conditions, mainly because of the thermal expansion mismatch of the different layers or the plastic deformation that can occur in the TBC layers. These residual stresses are maximum at low temperatures, since the creep processes acting at high temperatures induce stress relaxation, which allows the system to be considered as stress-free at high temperatures.

It is well accepted that these residual stresses tend to promote the debonding of coatings, leading to spontaneous spallation during the cycle cooling period. This is exactly the situation studied in Section 3.2.3.

In the four-point bending delamination test, these residual stresses may effectively interact with those derived from the applied load. The energy release rate relative to the bending moment applied to the system to drive the crack propagation can then be lower than what it would be without any residual stresses. The procedure to derive the critical energy release rate from the results of the 4-point bending tests must then be performed taking into account these residual stresses, contrary to what was done in the previous first data analysis. However, while stresses from two different loadings are simply additive in linear elasticity, the expression of the energy release rate will contain an interaction term in addition to the direct contributions of the individual sources.

The introduction of the residual stresses in our finite element computation of the energy release rate thus implies the simulation of the various steps of the experimental procedure, in particular the aging in the furnace for a specific number of cycles. This must be done for each item of data, the stored energy in the layers increasing with the aging duration as the stored energy in the thermally grown oxide layer due to its thickening. This finite element simulation itself induces some complications. The residual stresses in the oxide layer being significant, this layer of around $0.5-3 \mu \mathrm{m}$ should be meshed, leading to an excessive increasing number of degrees of freedom in the FE model. The 2D generalized plane strain assumption is no longer relevant, since the transverse thermal expansions (in the depth) of the different layers are not the same once the crack propagates (see Section 3.2.3). A complete 3D analysis would then be needed.

For the evaluation of the energy release rate relative to both the external forces and the residual stresses, it is better to have a method that allows the two solutions calculated for each input independently to be superimposed. However, as mentioned earlier, while the stresses, displacements, and strains from different sources can easily be added, different energy contributions cannot be superimposed by simple addition.

As stated in [65], a solution for the proper superposition of independent calculations (only external forces, only residual stresses) is to add a coupling term to them, as introduced in the 4-point bending analysis by Howard et al. [75]. The elastic energy release rate, taking into account the applied moment and residual stress, can then be obtained by the summation:

$$
G=G_{p}(M)+G_{r}\left(\sigma_{r e s}\right)+G_{p r}\left(M, \sigma_{r e s}\right)
$$

- $G_{p}(M)$ is the residual stress-independent contribution to the driving force and is the standard elastic fracture mechanics expression:

$$
G_{p}(M)=\frac{d W_{\text {ext }}}{d A}-\frac{d W_{\text {int }}}{d A}=F \frac{d u}{d A}-\frac{1}{2} F \frac{d u}{d A}=\frac{1}{2} F \frac{d u}{d A}
$$

where $F$ and $u$ are the applied load and corresponding displacement at the application point ( $d A$ is the elementary increase of fractured surface). 
- $G_{r}\left(\sigma_{r e s}\right)$ is the contribution from the residual stresses. This is the driving force available for crack extension with no applied load. It is obtained by the balance of the internal energy before and after the crack propagation, approximated by the difference between two calculations before and after the release of first crack tip nodes.

- $G_{p r}\left(M, \sigma_{\text {res }}\right)$ represents the interaction between the applied load and the residual stress distribution. For bending loading with residual stresses, this term is written [62] as:

$$
\left.G_{p r}\left(M, \sigma_{\text {res }}\right)=M\left(\kappa_{1} \text { (before }\right)-\kappa_{1}(\text { after })\right)
$$

where $M$ is the applied moment in the bending test and $\kappa_{1}$ is the curvature obtained before and after the crack growth, when considering only the residual stress contribution.

The contribution of the residual stresses to the actual critical energy release rate can be appreciated in Fig. 26, comparing the experimental evaluations when the residual stresses are taken into account and when they are not. The first term in (23) is obtained by the finite element solution and the node release technique, as indicated in Section 3.1. The terms $G_{r}\left(\sigma_{\text {res }}\right)$ and $G_{p r}\left(M, \sigma_{\text {res }}\right)$ have been evaluated analytically, considering a pure bending solution, similar to that given by Zhang et al. [67]. In this use, the energy released by residual stresses in each test is determined by assuming the delamination at the interface between the oxide layer and the ceramic topcoat. This is justified by the general observation of spallation, mainly at this interface in the majority of experiments on this TBC system, both on the specimens subjected to bending tests and the smaller coupons that serve to determine the spontaneous spallation (see below).

The expression (23) then allows the residual stresses induced by the thermal expansion mismatch to be taken into account easily in the bond coat, in the topcoat, and in the oxide layer (its thickness is one experimental input of this analysis). As shown in Fig. 26, the difference in the obtained critical energy release rate is not so significant, except for the long-term aging, where the stored energy is increasing (due to the increasing thickness of the oxide layer). Concerning the mixity angle associated with each kind of bending test, we have implicitly assumed that, due to the very limited change in the energy release rate, the mixity angle itself is not significantly modified.

\subsection{Final use of the results}

Finally, the whole set of experimental results, after the considered fittings, deliver a 3D map of the critical energy release rate versus the mode mixity from one side and thermal cycling on the other side, following the general expression (26).

$$
G_{c}=G_{c_{0}}\left(1+\frac{(1-\lambda)}{n} \tan ^{2}(\psi)\right)^{n} \exp \left[-A t \exp \left(-\frac{Q_{D}}{R T}\right)\right]
$$

where $G_{c_{0}}$ is the value of the Mode I critical energy release rate under 'as-received' conditions.

Such a general relation can be used to predict the lifetime corresponding to spontaneous spallation by the energetic approach proposed in [21]. In this approach, spontaneous spallation is predicted by comparing $G_{c}$ to the elastic stored energy at a given time and temperature. In such a case, the stored elastic energy $E_{\text {int }}$ comes exclusively from the thermal barrier system (no stiffening plate, no bending moment). This quantity may be given by analytical solutions based on the pure bending approximation (like in [72]). We then have spontaneous propagation when $E_{\text {int }} \geqslant G_{c}$.

The application of such an approach to spontaneous spallation was carried out as part of the Ph.D. Thesis of J.R. Vaunois [13], showing the capability to predict the lifetime before spallation of small TBC coupons (with the same thickness for all of the layers) subjected to thermal cycles (temperature cycles similar to those for the bending specimens in this study). These results are the subject of a future publication.
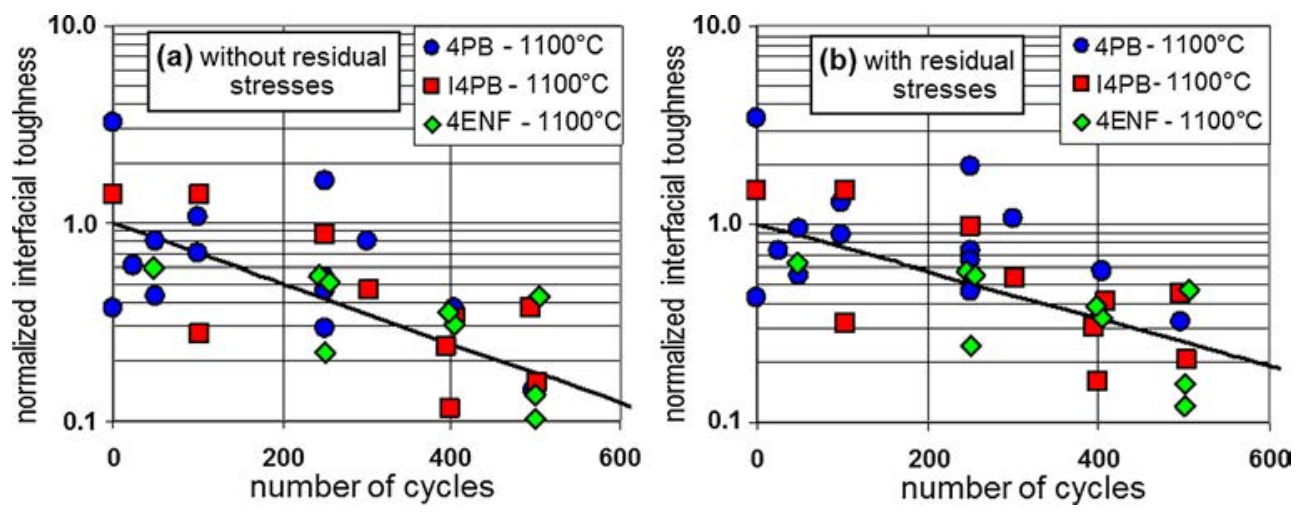

Fig. 26. Evolution of the normalized toughness at $1100^{\circ} \mathrm{C}$. (a) without residual stresses - (b) taking into account residual stresses. 


\section{Conclusions}

The EB-PVD TBC systems used in aircraft turbines usually fail because of the topcoat spallation resulting from interfacial cracking. The crack propagates along the interface under a mix of Mode I and Mode II delamination conditions, depending on the loading configuration and influenced by friction due to the interfacial roughness. The most common mechanisms leading to the interfacial fracture observed on ex-service components or burner rig specimens are edge delamination and buckling delamination. Both alike are driven by the largest compressive stress in the TGO and topcoat layers upon cooling down to room temperature, and correspond to near Mode II conditions. These two interfacial failure types control the TBC system lifetime, but the delamination toughness of the interface weakened in service by numerous complex processes cannot be predicted. Therefore, it is of prime importance to perform tests, in order to directly measure the adhesion of the TBC systems and their evolution during thermal exposure.

To date, all toughness data acquired for TBC systems at Onera by means of a 4-point bending test (4PB) are close to Mode I delamination, whereas the most relevant data according to the literature take place near Mode II conditions. The energy release rate required to propagate the interfacial crack becomes higher as the Mode II component becomes larger, and it is necessary to describe the mode-dependence of the interfacial toughness by a phenomenological law.

To this end, two additional 4-point-bending tests, the inverted 4-point bending (I4PB) and the 4-point end-notched flexure (4ENF) tests, have been developed. In these tests too, the stable steady-state interfacial cracking is used to infer the delamination toughness. However, these mechanical configurations are nearer to Mode II conditions.

Associated with the experimental developments, a computational method is proposed to derive the mode mixity angle for each adhesion test, besides the energy release rate. At the interface between two different materials, the crack propagates in mixed mode, influencing the interfacial toughness significantly. The modal mixity angle, depending on the contrast between the elastic properties of the materials (above and below the interface) and the load applied, requires a characteristic distance to the singularity to be defined for its evaluation. A method is proposed here, which provides a way to determine this characteristic distance. The main idea is to compare the true elastic energy release rate (as given by a perturbation method or by a node release technique) to the evaluation of the energy release rate as a function of the distance to the crack tip and obtained from the crack opening displacement field forward of the tip.

Finally, the adhesion energy of the interface between the bond coat and the ceramic topcoat (the oxide is not described) is measured from a significant number of bending tests under near Mode II conditions, respectively mixity angles of $-72.7^{\circ}$ and $-78.54^{\circ}$ for the I4PB and 4ENF configurations. It then makes it possible to reach the mode mixity obtained in the two ideal crack propagation cases (edging and buckling) from the literature and consistent with the spalled zones observed from feedback on ex-service blades. Despite obstacles to their implementation, the three bending tests (4PB, I4PB, and 4ENF) are quite effective to assess the interfacial adhesion in EB-PVD TBC systems under various mode mixity loading.

Another approach has been used, in which the process determining the toughness variation as a function of the mode mixity angle is taken in a different way. A characteristic length (or reference length) is treated as a fitting parameter for simultaneously determining both the mode mixity angle and the associated toughness. This method is based on a relation between the mode mixity angle and the toughness, which is directly deduced from the relation between the energy release rate and the stress intensity factors. By using one parameter less, it allows a good fit of the measured toughness data.

Moreover, in the 4-point bending delamination tests, the residual stresses induced by the thermal expansion mismatch in the bond coat, in the topcoat, and in the oxide layer generated during thermal cycling will interact with the stresses derived from the applied load. In order to obtain the intrinsic critical energy release rate, a specific superposition procedure is used to easily take into account the residual stresses. This results in a limited influence of the residual stresses, mainly for a long aging time. Finally, the whole set of generated data are used to define the evolution of the intrinsic interface toughness contingent on mode mixity and thermal cycling.

\section{Acknowledgments}

This investigation was partly funded by the French Civil Aviation Program Authority (Direction des Programmes de l'Aviation Civile) and the French Ministry of Defense procurement agency (Délégation Générale de l'Armement) under the Project "Durée de Vie des Structures Chaudes". Additional financial support from Snecma for PhD scholarship financing and for providing the TBCs examined in this study is gratefully acknowledged. In addition, the authors would like to thank Professor John W. Hutchinson (Harvard University) for insightful discussions about this work.

\section{References}

[1] Gleeson B. Thermal barrier coatings for aeroengine applications. J Propul Power 2006;22(2):375-83.

[2] Darolia R. Thermal barrier coatings technology: critical review, progress update, remaining challenges and prospects. Int Mater Rev 2013;58 (6):315-48.

[3] Clarke DR, Oechsner M, Padture NP. Thermal-barrier coatings for more efficient gas-turbine engines. MRS Bull 2012;37(10):891-8.

[4] Christensen A, Jarvis EAA, Carter EA. Atomic-level properties of thermal barrier coatings: characterization of metal-ceramic interfaces. In: Dressler RA, $\mathrm{Ng} \mathrm{C}$, editors. Chemical dynamics in extreme environments. Advanced series in physical chemistry. p. 490-546.

[5] Evans AG, Mumm DR, Hutchinson JW, Meier GH, Pettit FS. Mechanisms controlling the durability of thermal barrier coatings. Prog Mater Sci 2001;46 (5):505-53.

[6] Evans AG, He MY, Hutchinson JW. Mechanics-based scaling laws for the durability of thermal barrier coatings. Prog Mater Sci 2001;46(3-4):249-71. 
[7] Song P. Influence of material and testing parameters on the lifetime of TBC systems [Ph.D. dissertation]. Forschungszentrum Jülich GmbH Zentralbibliothek Verlag (eds): Energie \& Umwelt/Energy \& Environment; 2011, p. 137.

[8] Spitsberg IT, Mumm DR, Evans AG. On the failure mechanisms of thermal barrier coatings with diffusion aluminide bond coatings. Mater Sci Eng, A 2005;394(1):176-91.

[9] Yanar NM, Helminiak MA, Meier GH, Pettit FS. Comparison of the failures during cyclic oxidation of yttria-stabilized (7 to 8 weight percent) zirconia thermal barrier coatings fabricated via electron beam physical vapor deposition and air plasma spray. Metall Mater Trans A 2011;42A:905-21.

[10] Evans HE. Oxidation failure of TBC system: an assessment of mechanisms. Surf Coat Technol 2011;206(7):1512-21.

[11] Tolpygo VK, Clarke DR, Murphy KS. Oxidation-induced failure of EB-PVD thermal barrier coatings. Surf Coat Technol 2001:146-147:124-31.

[12] Tolpygo VK, Clarke DR. Morphological evolution of thermal barrier coatings induced by cyclic oxidation. Surf Coat Technol 2003;163-164:81-6.

[13] Vaunois JR. Modélisation de la durée de vie des barrières thermiques, par le développement et l'exploitation d'essais d'adhérence. Thèse de Doctorat de l'Université de Grenoble; 2013.

[14] Vidal-Setif MH, Chellah N, Rio C, Sanchez C, Lavigne O. Calcium-magnesium-alumino-silicate (CMAS) degradation of EB-PVD thermal barrier coatings: characterization of CMAS damage on ex-service high pressure blade TBCs. Surf Coat Technol 2012;208:39-45.

[15] Choi SR, Hutchinson JW, Evans AG. Delamination of multilayer thermal barrier coatings. Mech Mater 1999;31(7):431-47.

[16] Faulhaber S, Mercer C, Moon MW, Hutchinson JW, Evans AG. Buckling delamination in compressed multilayers on curved substrates with accompanying ridge cracks. J Mech Phys Solids 2006;54(5):1004-28.

[17] Hutchinson RG, Hutchinson JW. Lifetime assessment for thermal barrier coatings: tests for measuring mixed mode delamination toughness. J Am Ceram Soc 2011;94(s1):S85-95.

[18] Hutchinson JW, Suo Z. Mixed mode cracking in layered materials. Adv Appl Mech 1991;29:63-191.

[19] Leguillon D. Singularities and interfacial cracks. In: Braccini M, Dupeux M, editors. Mechanics of solid interfaces. ISTE-Wiley; 2013. p. 67-100.

[20] Martin E. Crack-interface interaction. In: Braccini M, Dupeux M, editors. Mechanics of solid interfaces. ISTE-Wiley; 2013. p. 189-210.

[21] Théry PY, Poulain M, Dupeux M, Braccini M. Spallation of two thermal barrier coating systems: experimental study of adhesion and energetic approach to lifetime during cyclic oxidation. J Mater Sci 2009;44(7):1726-33.

[22] Wang JS, Suo Z. Experimental determination of interfacial toughness curves using Brazil-nut-sandwiches. Acta Metall Mater 1990;38(7):1279-90

[23] Liechti KM, Chai YS. Asymmetric shielding in interfacial fracture under in plane-shear. J Appl Mech 1992;59(2):295-304.

[24] Charalambides PG, Cao HC, Lund J, Evans AG. Development of a test method for measuring the mixed mode fracture resistance of bimaterial interfaces. Mech Mater 1990;8(4):269-83.

[25] Evans AG, Rühle M, Dalgleish BJ, Charalambides PG. The fracture energy of bimaterial interfaces. Mater Sci Eng, A 1990;126(1-2):53-64.

[26] Suo Z, Hutchinson JW. Interface crack between two elastic layers. Int J Fract 1990;43:1-18.

[27] Davies P, Casari P, Carlsson LA. Influence of fibre volume fraction on mode II interlaminar fracture toughness of glass/epoxy using the 4ENF specimen. Composite Sci Technol 2005;65(2):295-300.

[28] Théry PY, Poulain M, Dupeux M, Braccini M. Adhesion energy of a YPSZ EB-PVD layer in two thermal barrier coating systems. Surf Coat Technol 2007;202(4-7):648-52.

[29] Kanouté P et al. Lifetime assessment tools for thermal barrier systems. In: Engineering conferences international, thermal barrier coatings IV, Irsee, Germany, June 22-27, 2014.

[30] Wang JS, Evans AG. Effects of strain cycling on buckling, cracking and spalling of a thermally grown alumina on a nickel-based bond coat. Acta Mater 1999;47(2):699-710.

[31] Wang JS, Evans AG. Measurement and analysis of buckling and buckle propagation in compressed oxide layers on superalloy substrates. Acta Mater 1998;46(14):4993-5005.

[32] Hutchinson JW, He MY, Evans AG. The influence of imperfections on the nucleation and propagation of buckling driven delaminations. J Mech Phys Solids 2000;48(4):709-34.

[33] Banks-Sills L, Ashkenazi D. A note on fracture criteria for interface fracture. Int J Fract 2000;103:177-88.

[34] Banks-Sills L. Interface fracture mechanics: theory and experiment. Int J Fract 2015;191:131-46.

[35] Hou PY, Saunders SRJ. A survey of test methods for scale adhesion measurement. Mater High Temp 2005;22(1-2):121-9.

[36] Saunders SRJ, Banks JP, Osgerby S, Rickerby D, Chunnilall CJ. An evaluation of tests for the adhesion of thermal barrier coatings. Mater Sci Forum $2001 ; 369-372: 775-84$

[37] Vasinonta A, Beuth JL. Measurement of interfacial toughness in thermal barrier coating systems by indentation. Eng Fract Mech 2001;68(7):843-60.

[38] Yan J, Leist T, Bartsch M, Karlsson AM. On cracks and delaminations of thermal barrier coatings due to indentation testing: experimental investigations. Acta Mater 2008;56(15):4080-90.

[39] Liu Y, Vidal V, Le Roux S, Blas F, Ansart F, Lours P. Influence of isothermal and cyclic oxidation on the apparent interfacial toughness in thermal barrier coating systems. J Eur Ceram Soc 2015:35(15):4269-75.

[40] Tanaka M, Liu YF, Kim SS, Kagawa Y. Delamination toughness of electron beam physical vapor deposition (EB-PVD) $\mathrm{Y}_{2} \mathrm{O}_{3}-\mathrm{ZrO}_{2}$ thermal barrier coatings by the pushout method: effect of thermal cycling temperature. J Mater Res 2008;23(09):2382-92.

[41] He L, Xu Z, Cao X, Zhong X, Mu R, He S. Adhesive strength of new thermal barrier coatings of rare earth zirconates. Vacuum 2009;83:1388-92.

[42] Banks-Sills L, Schwartz J. Fracture testing of Brazilian disk sandwich specimens. Int J Fract 2002;118:191-209.

[43] Hofinger I, Oechsner M M, Bahr HA, Swain MV. Modified four-point bending specimen for determining the interface fracture energy for thin, brittle layers. Int J Fract 1998;92:213-20.

[44] Bahr HA, Balke H, Fett T, Hofinger I, Kirchhoff G, Munz D, et al. Cracks in functionally graded materials. Mater Sci Eng, A 2003;362(1-2):2-16.

[45] Théry PY. Adhérence de barrières thermiques pour aube de turbine avec couche de liaison $\beta(\mathrm{Ni}, \mathrm{Pt}) \mathrm{Al}$ ou $\beta \mathrm{NiAl}(\mathrm{Zr})$, Thèse de Doctorat, Université Joseph Fourier, Grenoble; France, Matériaux et Génie des Procédés; 2007.

[46] Bacos MP, Dorvaux, JM, Lavigne O, Mévrel R, Poulain M, Rio C, et al. Performance and degradation mechanisms of thermal barrier coatings for turbine blades: a review of Onera activities, Aerosp Lab 3; 2011. <http://www.aerospacelab-journal.org>.

[47] Charalambides PG, Lund J, Evans AG, McMeeking RM. A test specimen for determining the fracture resistance of bimaterial interfaces. J Appl Mech 1989;56:77-82

[48] Yamazaki Y, Schmidt A, Scholz A. The determination of the delamination resistance in thermal barrier coating system by four-point bending tests. Surf Coat Technol 2006;201(3-4):744-54.

[49] Zhao PF, Sun CA, Zhu XY, Shang FL, Li CJ. Fracture toughness measurements of plasma-sprayed thermal barrier coatings using a modified four-point bending method. Surf Coat Technol 2010;204(24):4066-74.

[50] Eberl C, Wang X, Gianola DS, Nguyen TD, He MY, Evans AG, et al. In situ measurement of the toughness of the interface between a thermal barrier coating and a Ni alloy. J Am Ceram Soc 2011;94(S1):S120-7.

[51] Mazot P, de Fouquet J. Détermination par la méthode de résonance des constantes d'élasticité de monocristaux de superalliage base nickel AM1 entre l'ambiante et $1100^{\circ} \mathrm{C}$. Mémoires et Etudes Scientifiques, Revue de Métallurgie 1992:165-70.

[52] Kim S, Liu Y, Kagawa Y. Evaluation of interfacial mechanical properties under shear loading in EB-PVD TBCs by the pushout method. Acta Mater 2007;55(11):3771-81.

[53] Pan D, Chen MW, Wright PK, Hemker KJ. Evolution of a diffusion aluminide bond coat for thermal barrier coatings during thermal cycling. Acta Mate 2003;51(8):2205-17.

[54] Zhao X, Wang X, Xiao P. Sintering and failure behaviour of EB-PVD thermal barrier coating after isothermal treatment. Surf Coat Technol 2006;200(2021):5946-55. 
[55] Schuecker C, Davidson BD. Evaluation of the accuracy of the four-point bend end-notched flexure test for mode II delamination toughness determination. Compos Sci Technol 2000;60(11):2137-46.

[56] Fan C, Ben Jar PY, Roger Cheng JJ. A unified approach to quantify the role of friction in beam-type specimens for the measurement of mode II delamination resistance of fibre-reinforced polymers. Compos Sci Technol 2007;67(6):989-95.

[57] Rice JR. Elastic fracture mechanics concepts for interfacial cracks. J Appl Mech 1988;55(1):98-103.

[58] Rice JR, Suo Z, Wang JS. Mechanics and thermodynamics of brittle interfacial failure in bimaterial systems. In: Rühle M, Evans AG, Ashby MF, Hirth JP, editors. Metal-Ceramic Interfaces, Acta Scripta Metallurgica Proceedings Series, vol. 4. Pergamon Press; 1990. p. 269-94.

[59] Thouless MD, Evans AG, Ashby MF, Hutchinson JW. The edge cracking and spalling of brittle plates. Acta Metall 1987;35(6):1333-41.

[60] Rice JR, Sih GC. Plane problems of cracks in dissimilar media. J Appl Mech 1965;32(2):418-23.

[61] Willis JR. Fracture mechanics of interfacial cracks. J Mech Phys Solids 1971;19(6):353-68.

[62] Laurencin J. Amorçage et propagation d'une fissure à l'interface d'un bi-matériau. France: Mémoire CNAM Grenoble; 2002.

[63] Tvergaard V, Hutchinson JW. The influence of plasticity on mixed mode interface toughness. J Mech Phys Solids 1993;41(6):1119-35.

[64] Matos PPL, McMeeking RM, Charalambides PG, Drory MD. A method for calculating stress intensities in bimaterial interfaces. Int J Fract 1989;40:235-54.

[65] Delette G, Huchet G, Laurencin J. Étude des sollicitations mécaniques aux interfaces d'un empilement de couches minces. Application à la mesure d'adhérence par la technique de flexion 4 points. In: $18^{\text {ème }}$ Congrès Français de Mécanique (eds) AFM, Maison de la Mécanique, Courbevoie, France; 2007. <http://hdl.handle.net/2042/15981> [accessed 30 August 2007].

[66] Malyshev BM, Salganik RL. The strength of adhesive joints using the theory of cracks. Int J Fract 1965;1(2):114-28.

[67] Z-set Material and structure analysis suite. <http://www.zset-software.com>.

[68] Parks DM. A stiffness derivative finite element technique for determination of crack tip stress intensity factors. Int J Fract 1974;10(4):487-502.

[69] Krueger R. Virtual crack closure technique: history, approach and applications. Appl Mech Rev 2004;57(2):109-43.

[70] Howard SJ, Tsui YC, Clyne TW. The effect of residual stresses on the debonding of coatings - I. A model for delamination at a bimaterial interface. Acta Metall Mater 1994;42(8):2823-36.

[71] Zhang XC, Xu BS, Wang HD, Wu YX. An analytical model for predicting thermal residual stresses in multilayer coating systems. Thin Solid Films $2005 ; 488(1-2): 274-82$.

[72] Vaunois JR, Dorvaux JM, Kanouté P, Chaboche JL. A new version of a rumpling predictive model in thermal barrier coatings. Eur J Mech A/Solids 2013:42:402-21.

[73] Comninou M. The interface crack. J Appl Mech 1977;44:631-6.

[74] Comninou M. The interface crack in a shear field. J Appl Mech 1978;45:287-90.

[75] Howard SJ, Phillipps AJ, Clyne TW. The interpretation of data from the four-point bend delamination test to measure interfacial fracture toughness. Composites 1993;24(2):103-12. 